\title{
Estudo comparativo de equilíbrio de oxigênio no sangue de 40 gêneros de peixes da Amazônia (*)
}

\author{
Dennis A. Powers ('); Hans J. Fyhn $\left({ }^{2}\right)$; Unni E. H. Fyhn $\left({ }^{2}\right)$; Joseph P. Martin $\left({ }^{3}\right)$; Robert L. Garlick $\left({ }^{4}\right)$; \\ Stephen C. Wood $(5)$
}

\begin{abstract}
Resumo
Examinamos a afinidade pelo oxigênio do sangue total e intacto de representantes de 40 gêneros de peixes da Amazônia. Foram considerados todos os peixes de respiração aérea e branquial e nenhuma diferenciação na afinidade pelo oxigênio pode ser distinguivel, embora nos dois casos de espécies próximas i. e. Osteoglossum de respiração branquial versus Arapaima de respiração aérea e Hoplias de respiração branquial versus Hoplerythrinus de respiração aérea; os de respiração aérea têm o sangue com mais afinidade pelo oxigênio do que os de respiração branquial. Significativas diferenças na afinidade pelo oxigênio foram encontradas quando foram considerados o habitat dos peixes: as afinidades pelo oxigênio foram em geral correlacionadas com o oxigênio disponível no meio ambiente e as demandas relativas de oxigênio dos peixes.
\end{abstract}

\section{INTRODUÇÃo}

Desde que há profundas diferenças entre o modo de vida aquática e terrestre, considerável atenção tem sido concentrada nos processos evolucionários envolvidos na transição da forma aquática aos meios ambientes terrestres. De particular interesse tem sido a evolução dos órgãos de respiração aérea, incluindo pulmões, sistema circulatório e sangue ou afinidade de hemoglobina pelo oxigênio.

Em 1937, McCutcheon \& Hall encontraram uma diminuição da afinidade pelo oxigênio nas espécies que são consideradas importantes formas de transição na evoluçảo do meio ambiente aquático ao terrestre. Estas e outras teorias têm sido interpretadas como uma alta e constante adaptação evolucionária às variações de oxigênio nos meios ambientes aéreos.
Um particular e interessante exemplo tem sido proporcionado por Lenfant \& Johansen (1967). Eles examinaram três espécies de anfíbios (Necturus, Amphiuma, Rana) tentando estudar as mudanças na afinidade pelo oxigênio em relação à transição entre a respiração aquática e aérea. Necturus, cujos pulmões são essencialmente inoperantes, foi considerado o mais dependente de respiração aquática. Ao outro extremo foi a rã, Rana, a qual como adulto depende principalmente da respiração aérea. Amphiuma foi considerada intermediária entre Necturus e Rana. Os pesquisadores observaram no sangue uma diminuiçäo da afinidade pelo oxigênio visto que se torna uma pronunciada dependência da respiração aérea. Como a respiração aérea verdadeiramente tem ocorrido em peixes anteriores à evolução de anfibios, a morfologia e fisiologia comparada das ramificações em peixes tem sido estudadas pormenorizadamente (ver revisão de Thompson, 1969: Johansen, 1970). Johansen \& Lenfant (1972) compararam as curvas de equilíbrio de oxigênio em três zonas temperadas, peixes com respiração branquial com vários de respiração aérea (na maioria tropicais) e conclui que: "uma clara tendência é evidente, na forma de respiração aérea, ter uma hemoglobina de baixa afinidade pelo oxigênia". Esta descoberta apresenta ser consistente com o exemplo de anfíbio descrito anteriormente. No entanto, os peixes de diferentes regiōes do mundo (i.e. temperadas e tropicais) e visto que os peixes, em geral, estão ocupando uma grande variedade de nichos, é concebível que as afinidades pelo oxigênio observadas por Johansen e outros são adaptações evolu-

$\left({ }^{\bullet}\right)$-Versão original inglesa publicada em Comp. Biochem. Physiol. vol. 62A (1). 1979.

(1) - Department of Biology, Johns Hopkins University Baltimore, Maryland, 21218.

(2) - Institute of Zoophysiology, University of Oslo, Blindern, Oslo 3. Norway.

(3) - Department of Zoology, Duke University Marine Laboratory, Beaufort, N. C. 28516

(4) - Department of Zoology, University of Texas, Austin, Texas 78712.

(5) - Department of Physiology, University of New Mexico, Albuquerque, New Mexico 87106. 
cionárias a nichos ecológicos específicos mais do que um reflexo de um desenvolvimento evolucionário no sentido da respiração aérea. Temos examinado o equilíbrio de oxigênio do sangue de vários peixes da Amazônia, que vivem, em geral, na mesma região tropical, mas cujos nichos ecológicos e modos de respiração variam. Respiração aérea obrigatória, respiração aérea facultativa e respiração branquial obrigatória, têm sido examinadas na esperança de que nosso conhecimento sobre a ecologia fisiológica destes peixes possa ser desenvolvido.

\section{MATERIAIS E MÉTodos}

Os peixes foram sangrados de acordo com o método traçado por Fyhn et al. (1978) .

As curvas de oxigenação do sangue total foram determinadas com um analisador de dissociação de oxigênio, "Aminco Hem-O-Scan", expondo as amostras de sangue a variadas pressões de oxigênio e medida a porcentagem de oxi - hemoglobina.

O elétrodo de oxigênio foi calibrado, deixando o compartimento da amostra (Fig. 1) saturado com gás humidificado à temperatura constante. O elétrodo foi calibrado de acordo com a pressão barométrica existente. Mais tarde, o comportamento da amostra foi completamente desoxigenado com nitrogênio ou argon de altíssima pureza $(99,999 \%)$. O uso do zero desoxigenado em vez de um zero eletrônico elimina diversas correntes electrônicas não específicas. Este procedimento de zero aperfeiçoa a precisão das medidas de baixos $\mathrm{pO}_{2}$, especialmente quando o regulador de resistência foi usado para expandir o sinal do elétrodo de oxigênio.

Uma vez que o aparelho foi calibrado, sangue humana e/ou hemoglobina $\mathrm{Hb} \mathrm{A}$ humana (2.7 mM Hb A em 0.1 M Tris- $\mathrm{HCl}, \mathrm{pH} 7.4 \mathrm{com}$

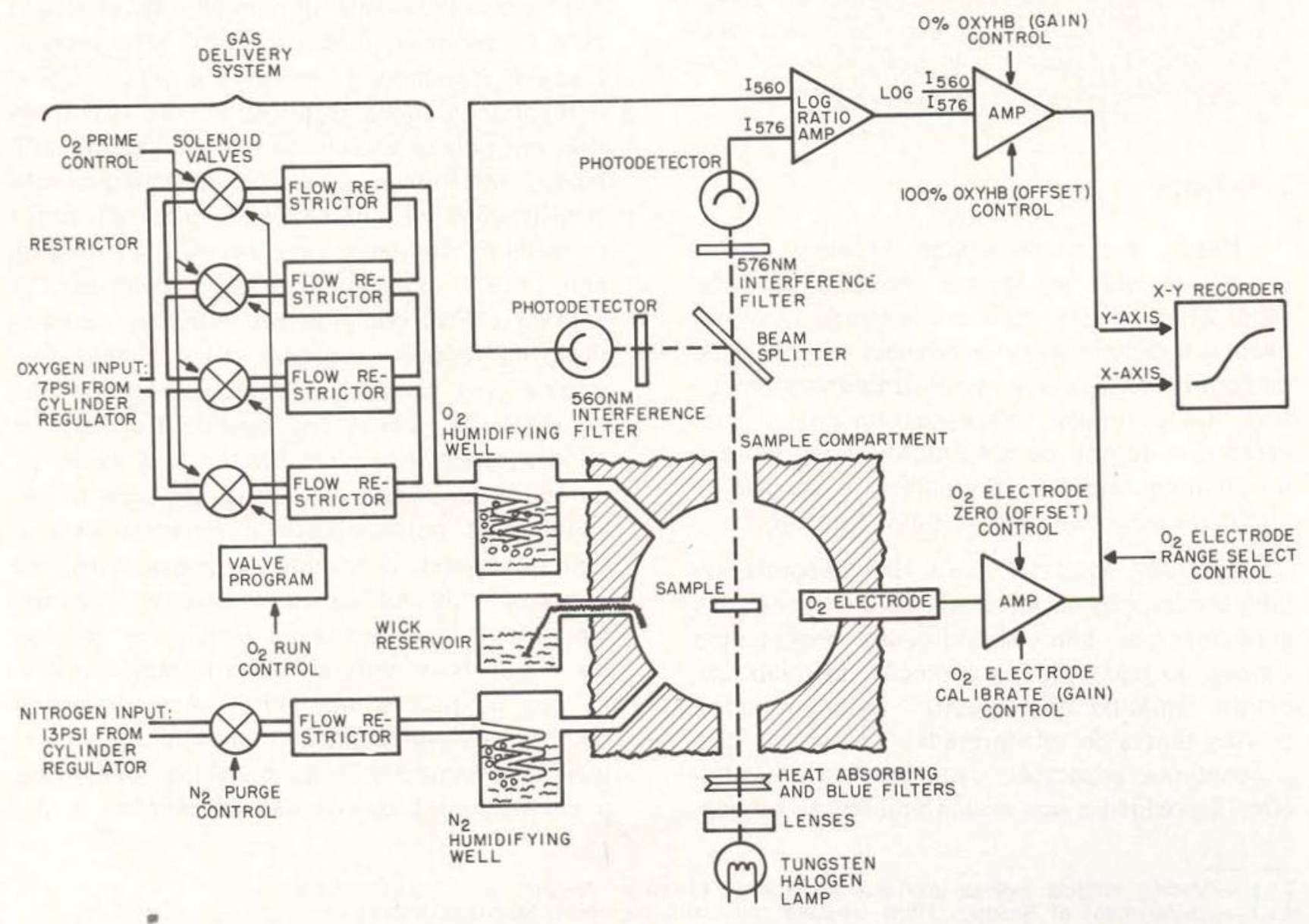

Fig. 1 - Diagrama funcional do analisador de dissociação de oxigênio (com autorização de American Instruments Company, Silver Sping, Maryland). 
$0.1 \mathrm{M} \mathrm{NaCl}$ ) foi analisado como teste de funcionamento do aparelho. Alíquota de $3 \mu \mathrm{l}$ de sangue ou solução de hemoglobina foi adicionada numa lamínula de vidro esférica $n^{\circ} 2$, de $18 \mathrm{~mm}$ de espessura, sendo a solução coberta por um pedaço de membrana circular de um copolimero de silicona. Todas as bolhas de ar debaixo da membrana foram eliminadas. A amostra foi pressionada com o conjunto "Aminco" de preparação de amostra. A amostra preparada foi colocada no espaço do conjunto e introduzida na câmara do compartimento da amostra. A desoxigenação foi acompanhada por expulsão do compartimento da amostra com nitrogênio ou argon de altíssima pureza $(99,999 \%)$. A curva de equilíbrio de oxigênio foi gerada por exposição da amostra a incrementos graduais de pressōes parciais de oxigênio, as quais alcançam uma velocidade de $5 \mathrm{~mm} \mathrm{Hg}$ por minuto e medida a porcentagem de oxigênio espectrofotometricamente, enquanto que a tensão de oxigênio foi avaliada com um elétrodo de oxigênio'. As duas variáveis foram registradas por $X$ e $Y$ dando um gráfico de porcentagem de hemoglobina em função do $\mathrm{pO}_{2}$.

Os cilindros de gases foram emparelhados com $21 \%$ ou $25 \%$ de oxigênio no cilindro de ar, e $99,999 \%$ de nitrogênio, no cilindro de nitrogênio (pode ser usado Argon) ('). Quando $0 \mathrm{CO}_{2}$ foi usado na mistura gasosa, foi adicionado, a cada um, o cilindro de gás apropriado. Por exemplo, o máximo de $\mathrm{CO}_{2}$ empregado foi de $5,6 \%$, no qual foram usados ambos os cilindros de ar e nitrogênio. Ademais, para cada série de gases a $\mathrm{pCO}_{2}$ foi constante, para qualquer análise em particular. A uniformidade da $\mathrm{pO}_{2}$ dentro da câmara teste foi mantida por um aparelho homogenizador.

A câmara de água do compartimento da amostra a humidificadores foram conectados a um circulador externo que foi empregado para controlar a temperatura. A humidade foi regulada por um bom acondicionamento do gás e da tomada de acesso do compartimento da amostra (Fig. 1). O acondicionamento produz gás úmido à temperatura constante. $\mathrm{O}$ compartimento da amostra foi mantido essencialmente a $100 \%$ de saturação de água por uma tomada fornecedora.

A $\mathrm{pO}_{2}$ do compartimento da amostra foi registrada pelo elétrodo de oxigênio de Clark. A sinal foi amplificada e registrada no eixo- $X$ do registro $X-Y$. O resultado e compensação foram controlados por uma série de aparelhos de resistência calibrados e variáveis.

A fonte de luz emana de uma lâmpada de tungstênio de 12 volt, 20 watt philips $\neq 12452$. A fig. 1 ilustra como um raio de luz passa através da amostra desintegrando o raio, e após dirigido para dois fotodectores; cada um com diferente filtro de interferência (i.e. um transmite a $560 \mathrm{~nm}$ e outro a $576 \mathrm{~nm}$ ). Os produtos dos fotodetectores foram processados por um amplificador que produz um sinal proporcional à diferença de absorbância a $560 \mathrm{~nm}$ e $576 \mathrm{~nm}$. Embora estes filtros fossem usados em nossos experimentos, outros comprimentos de onda podem ser selecionadas por uma apropriada interferência de filtros (e.g. uma destas transmissões a $410 \mathrm{~nm}$ ). O sinal resultante da diferença de comprimento de onda $\left(\log \frac{1560}{1576}\right)$ foi canalizada através de outro amplificador cujo resultado e equivalência foram controlados por um "resistor" variável (i.e. controle de oxi-hemoglobina) na parte superior do aparelho. A saída final deste amplificador foi conectada com o eixo $\mathrm{Y}$ do registro $\mathrm{X}-\mathrm{Y}$.

Quando o valor de hemoglobina humana ( $\mathrm{Hb}$ A) harmonizada com os valores padrões visados $\left(P_{50}=5 \mathrm{~mm} \mathrm{Hg}\right.$ e $21,5^{\circ} \mathrm{C}, 0.1 \mathrm{M}$ TrisHC1, pH 7, 4, 0,1 M NaC1 com 1 mM EDTA) foram processadas as amostras de peixes. Quando o valor de $\mathrm{Hb} A$ não coincidia com os valores visados, o aparelho foi recalibrado com uma nova membrana no elétrodo de oxigênio e analisada uma amostra fresca de $\mathrm{Hb} \mathrm{A}$.

A maioria do sangue do peixe foi analisada na presença e ausência de $\mathrm{CO}_{2}$. $\mathrm{Na}$ ausência de $\mathrm{CO}_{2}$, o pH do sangue foi usualmente alto, o suficiente para que a correção do efeito Root fosse presumivelmente desnecessária. No en-

(1) * Para hemoglobina de alta afinidade, poderia ser usada uma velocidade de fluxo menos que $5 \mathrm{~mm} \mathrm{Hg}$. Isto é efetuado por mediçōes, feitas com gases que contém $5 \%$ ou menos de oxigênio. No entanto, o máximo volume é obtido por um aparelho de fluxo variável que permite gerar qualquer mistura de gás desejado por meio de um fluorómetro e gases padrōes definidos. Tais procedimentos têm sido recentemente usado por nós, melhorando significativamente a parte inferior da curva de uniāo de oxigênio. 
tanto, na presença de $5,6 \%$ de $\mathrm{CO}_{2}$, o efeito Root foi a miúdo significativo para as amostras de sangue de algumas espécies de peixes. Como cada amostra é individualmente calibrada a uma saturação aparente de $100 \%$, calibração $100 \%$ pode estar com erro para estas espécies com pronunciado efeito Root. (i.e. quando o $\mathrm{pH}$ do sangue é baixo, especialmente na presença de $\mathrm{CO}_{2}$ ).

O efeito Root foi detectado da seguinte maneira. A amostra foi calibrada na ausência de $\mathrm{CO}_{2}$ onde $\mathrm{o} \mathrm{pH}$ do sangue estava entre $\mathrm{pH} 7,6$ e pH 8,2 e o efeito Root foi considerado ausente $\left({ }^{2}\right)$. A fonte de gás foi então mudada de modo que o gás equilibrado tivesse $5,6 \%$ $\mathrm{CO}_{2}$ e o sangue foi reequilibrado com o novo gás. Uma diminuição no nível de $100 \%$ de saturação $(\Delta Y)$ foi tomada como índice de efeito Root na hemoglobina. Como a lisia das células, formação de meta hemoglobina e também diluição diminui o nível de saturação de $100 \%$, a experiência reversa também foi executada, para determinar o incremento na porcentagem de saturação $(\Delta \mathrm{Y})$ quando $\circ \mathrm{CO}_{2}$ foi removido do equilíbrio de gases. Podemos presumivelmente, corrigir o efeito Root por:

Onde :

$$
\mathrm{Y}_{\mathrm{CO}_{2}}^{\text {corrigido }}=\frac{\mathrm{Y}_{\mathrm{CO}_{2}} \begin{array}{l}
\text { aparente } \\
(100-\Delta \mathrm{Y})
\end{array}}{\mathrm{Y}_{\mathrm{ar}}}
$$

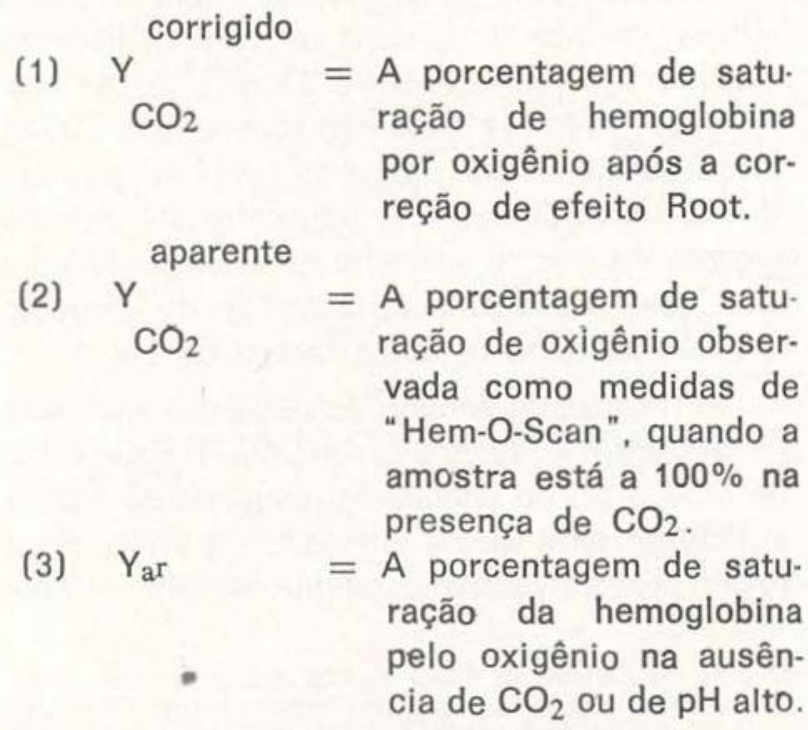

(4) $\Delta Y$

$=\mathrm{A}$ diminuição de saturação de hemoglobina pelo oxigênio devida ao efeito Root.

Várias fontes de erros existem em tais correções, de modo que se deveriam considerar as curvas cuidadosamente corrigidas. O recente desenvolvimento de uma célula de amostra com uma senda de comprimento constante para o "Scan-Hem-O - " poderia fazer futuramente desnecessárias as correções do efeito Root.

Relataremos valores $\mathrm{P}_{50}$ para o estudo de sangue na ausência de $\mathrm{CO}_{2}$, mas o $P_{50}$ observado $\left(P_{50}\right.$ aparente) poderia ser usado para estudos que tenham $5.6 \% \mathrm{CO}_{2}$ no equilíbrio de gases. O $P_{50}$ oparente é a pressão parcial correspondente à metade da saturação de hemoglobina por oxigênio. Claramente, o $P_{50}$ aparente $\leqslant \mathrm{P}_{50}$, e quando o efeito Root não está presente o $\mathrm{P}_{50}$ aparente $=\mathrm{P}_{50}$ (Tabela I) .

$\mathrm{Na}$ maioria dos casos (Tabela I) o efeito Bohr foi determinado em amostras individuais, mas muitas foram obtidas pelo registro do log $P_{50}$ versus $\mathrm{pH}$ do sangue numa série de pontos e calculando o efeito Bohr pela inclinação, $\Delta \log \mathrm{P}_{50} / \Delta \mathrm{pH} . O \mathrm{P}_{50}$ ao $\mathrm{pH}$ do sangue foi estimado, medindo-se o $\mathrm{pH}$ do sangue desoxi e o $\mathrm{pH}$ do sangue oxigenado e tomada a média dos dois valores. $\mathrm{O} \mathrm{pH}$ do sangue foi medido por uma unidade de micro pH "Radiometer" BMS-2, de marca II, Copenhagen, Dinamarca. Pela técnica empregada, o $P_{50}$ do sangue com um pronunciado efeito Root não pode ser exatamente medido na faixa de $\mathrm{pH}$ onde o efeito Root é operante. Por conseguinte, o efeito Bohr foi somente calculado em faixas de $\mathrm{pH}$ alto onde a contribuição de efeito Root é presumivelmente insignificante. Se um peixe tem o sangue com um pronunciado efeito Root, pode esperar-se o efeito Bohr ser substancialmente maior a baixos valores $\mathrm{pH}$.

\section{RESUltados E Discussão}

Em continuação, usaremos uma série de termos ecológicos, cujas definições, a miúdo, tem ligeiras variaçōes. O habitat de água doce pode dividir-se em duas regiões:

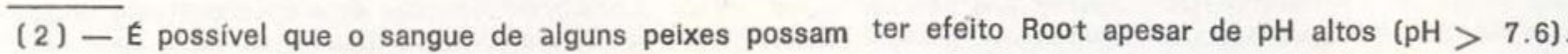


A primeira é a lêntica, habitat de água em repouso, incluindo, charcos, pântanos e lamaçal. O segundo é o lótico ou habitat de águas rápidas que inclui riachos, enseadas e rios. O oxigênio e o dióxido de carbono, a miúdo. são restritos em água doce embora não o sejam no meio ambiente marinho. Em geral, o habitat lêntico apresenta grandes variações de oxigênio dissolvido e o $\mathrm{pO}_{2}$ pode alcançar valores abaixo de $5 \mathrm{~mm} \mathrm{Hg}$ em regiōes pantanosas (Tabela II, Willmer, 1934). Por outro lado, o meio ambiente lótico usualmente tem regiōes com menor variaçōes de oxigênio dissolvido. Os rios, normalmente, têm altas concentrações de oxigênio, maiores do que em igarapés e riachos (Tabela II) mas dentro de qualquer sub-habitat, o oxigênio dissolvido é relativamente constante. Este é um agudo contraste com o charco lêntico, onde o oxigênio dissolvido na superfície pode alcançar a saturação enquanto que as águas do fundo podem ser essencialmente faltas de oxigênio.

Os organismos podem ser classificados de acordo com seu sub-habitat ou zona de habitat geral. Por exemplo, em charcos lênticos, há três zonas; zona litoral, zona limnótica e zona profunda. Destas três zonas, só duas formas nos interessam. A zona litoral de águas pouco profundas, região pantanosa onde a luz penetra até o fundo. A zona limnótica é uma área de água aberta de uma profundidade de efetiva penetraçăo. No habitat lótico, há dois subhabitats ou zonas:

(1) A zona de correnteza onde a velocidade da água é muito grande a ponto de exigir que o peixe seja um forte nadador (2) e as zonas lentas onde a velocidade da água é lenta e os peixes não são obrigados a ser péritos nadadores. Outro tipo de classificação de habitat está baseado no modo de vida que segue o organismo. Estamos interessados com os habitats bênticos, epibênticos, pelágicos e neustônico. Os peixes bênticos vivem no sedimento do fundo enquanto que epibênticos vivem no fundo ou acima do fundo. Os peixes pelágicos nadam livremente e percorrem o meio ambiente aquático dos arredores, enquanto que os peixes neustônicos nadam na superfície da água.

Na Tabela I, usamos a categoria específica de habitat, a qual se refere à área dentro do habitat geral. Neste assunto, devemos intro- duzir uma nota de aviso referente à categoria ecológica destes peixes. O pouco conhecimento disponível da sistemática sem mencionar a ecologia destes peixes. Com isto em mente, tivemos que recorrer à literatura, à experiência pessoal e aos consultores de experiência (ver Tabela I) .

O sangue de representantes de 40 gêneros de peixes da Amazônia foi examinado e seus resultados são resumidos na tabela $\mathrm{I}$, e na figura 2-38. $O$ equilíbrio de oxigênio foi determinado a $30^{\circ} \mathrm{C}$, o qual inclui a temperatura de seu ambiente natural $\left(28^{\circ} \mathrm{C}-33^{\circ} \mathrm{C}\right.$, Reiss, 1977). Em alguns casos, (Tabela I) a curva de equilíbrio de oxigênio também foi determinada a $20^{\circ} \mathrm{C}$.

Três espécies cartilaginosas de peixes foram examinadas. Todas foram arraias do gênero Potamotrygon. A figura 2 ilustra uma curva de dissociação de oxigênio para uma espécie, ambas na presença e ausência de $5.6 \%$. Na ausência de $\mathrm{CO}_{2}$, as três espécies têm sangue com afinidade pelo oxigênio similar $\left(P_{50}\right.$ próximo a $12 \mathrm{~mm} \mathrm{Hg}$ a um $\mathrm{pH}$ do sangue de 7,6 ) e na presença de $5,6 \%$ de $\mathrm{CO}_{2}$, as curvas de equilíbrio de oxigênio foram modificadas levemente para a direita (Tabela I). Não foi observado efeito Root no sangue total de Potamotrygon. O efeito Bohr foi pequeno (ver tabela I), e similar no eritrócito e hemoglobina de arraia marinha medindo a $10^{\circ} \mathrm{C}-$ $11^{\circ} \mathrm{C}$ (Maxwell, 1958).

$\mathrm{O}$ sangue do peixe pulmonado da América do Sul, Lepidosiren paradoxa, foi estudado nas duas temperaturas $\left(20^{\circ} \mathrm{C}\right.$ e $\left.30^{\circ} \mathrm{C}\right)$; ambas na presença e ausência de $5.6 \% \mathrm{CO}_{2}$. A Tabela I mostra que a temperatura atinge principalmente o equilíbrio de oxigênio do sangue. Além disso, o sangue na presença e ausência de $\mathrm{CO}_{2}$, apresenta alta afinidade de oxigênio relativa aos outros peixes testados. A Figura 3 ilustra a curva de equilíbric de oxigênio para estas espécies $\left(30^{\circ} \mathrm{C}\right)$. Como o peixe pulmonado é de respiração aérea abrigatória, este resultado é inconsistente com a noção de que os de respiração aérea devem ter $\mathrm{P}_{50}$ maiores que os de respiração aquática. (Johansen \& Lenfant, 1972). Não houve efeito Root detectável e o efeito Bohr relativamente pequeno $(-0,33)$. Nossos dados são similares aos de Johansen \& Lenfant (1967), que encontraram: 
TABELA I - Parâmetros de sangue e classificação ecológica de peixes amazônicos

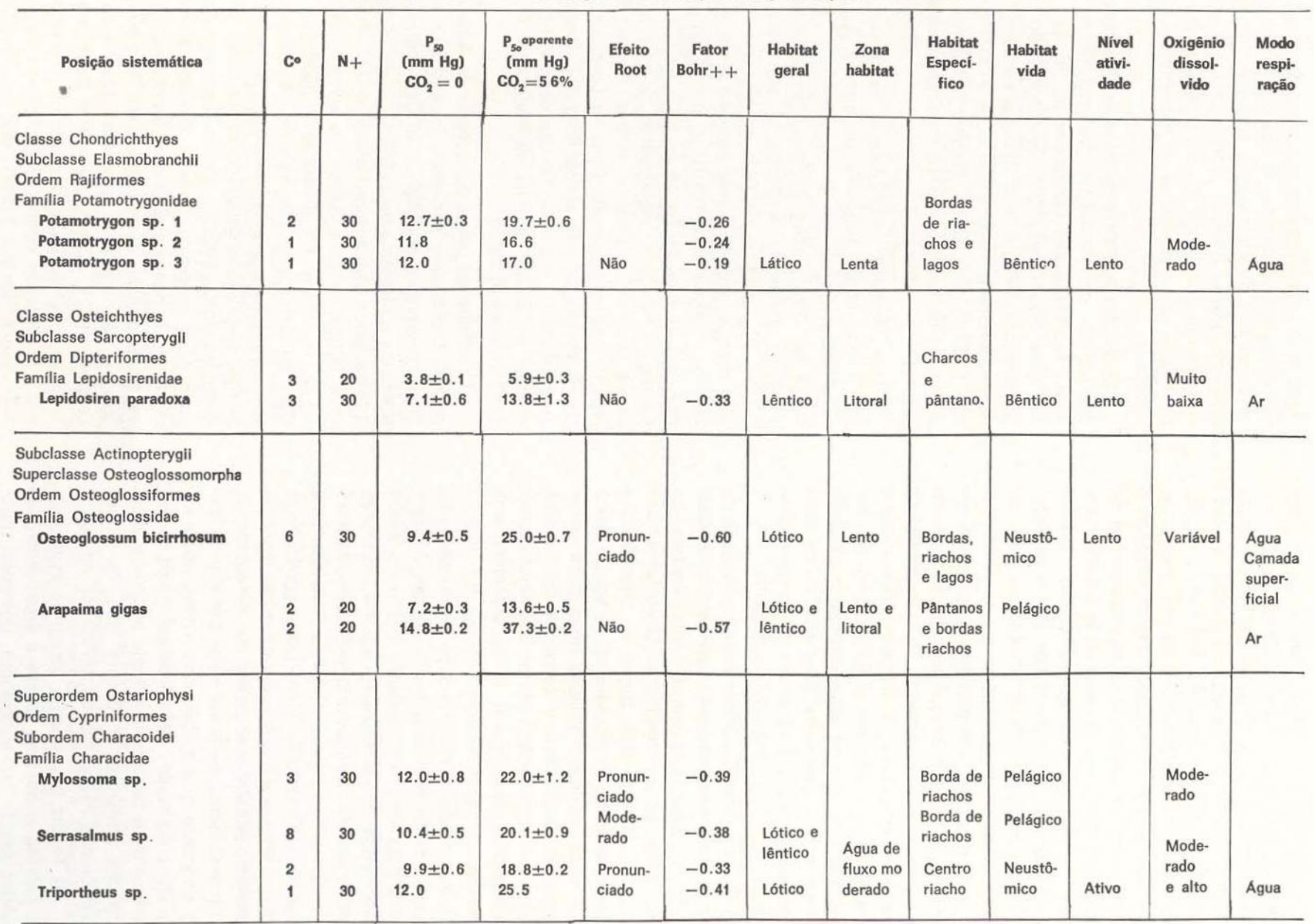


TABELẠ I - Continuaçāo

\begin{tabular}{|c|c|c|c|c|c|c|c|c|c|c|c|c|c|}
\hline Posição sistemática & Co & $\mathrm{N}+$ & $\begin{array}{c}P_{50} \\
\left(\mathrm{~mm} \mathrm{Hg}^{\mathrm{Hm}}\right. \\
\mathrm{CO}_{2}=0\end{array}$ & $\begin{array}{l}P_{50} \text { aparente } \\
\text { (mm Hg) } \\
\mathrm{CO}_{2}=56 \%\end{array}$ & $\begin{array}{r}\text { Efeito } \\
\text { Root }\end{array}$ & $\begin{array}{c}\text { Fator } \\
\text { Bohr++ }\end{array}$ & $\begin{array}{c}\text { Habitat } \\
\text { geral }\end{array}$ & $\begin{array}{c}\text { Zona } \\
\text { habitat }\end{array}$ & $\begin{array}{l}\text { Habitat } \\
\text { Especi- } \\
\text { fico }\end{array}$ & $\begin{array}{l}\text { Habitat } \\
\text { vida }\end{array}$ & $\begin{array}{l}\text { Nivel } \\
\text { ativi- } \\
\text { dade }\end{array}$ & $\begin{array}{l}\text { Oxigênio } \\
\text { dissol- } \\
\text { vido }\end{array}$ & $\begin{array}{l}\text { Modo } \\
\text { respi- } \\
\text { ração }\end{array}$ \\
\hline $\begin{array}{l}\text { Família Erythrinidae } \\
\text { Hoplias malabaricus } \\
\text { Hoplerythrinus unitaenlatus }\end{array}$ & $\begin{array}{l}4 \\
1\end{array}$ & $\begin{array}{l}30 \\
20 \\
30\end{array}$ & $\begin{array}{l}4.8 \pm 0.3 \\
3.4 \pm 0.4 \\
11.4\end{array}$ & $\begin{array}{l}16.4 \pm 0.2 \\
27.1 \pm 4.9 \\
36.2\end{array}$ & $\begin{array}{l}\text { Mode- } \\
\text { rado }\end{array}$ & $\begin{array}{l}-0.48 \\
-0.63 \\
-0.75\end{array}$ & $\begin{array}{l}\text { Lótico e } \\
\text { lêntico }\end{array}$ & $\begin{array}{l}\text { Lento e } \\
\text { litoral }\end{array}$ & $\begin{array}{l}\text { Bordas } \\
\text { riachos e } \\
\text { Charcos }\end{array}$ & $\begin{array}{l}\text { Epibên- } \\
\text { tico e } \\
\text { Pelágico }\end{array}$ & $\begin{array}{l}\text { Mode- } \\
\text { rado }\end{array}$ & $\begin{array}{l}\text { Mode- } \\
\text { rada- } \\
\text { mente } \\
\text { lento }\end{array}$ & $\begin{array}{l}\text { Agua } \\
\text { Bimodal }\end{array}$ \\
\hline $\begin{array}{l}\text { Família Cynodontidae } \\
\text { Rhaphiodon vulpinus }\end{array}$ & 2 & 30 & $10.7 \pm 0.9$ & $38.1 \pm 1.1$ & $\begin{array}{l}\text { Pronun- } \\
\text { ciado }\end{array}$ & -0.69 & Lótico & Rápido & $\begin{array}{l}\text { Centros } \\
\text { riachos }\end{array}$ & $\begin{array}{l}\text { Pelágico } \\
\text { Neustô- } \\
\text { nico }\end{array}$ & Ativo & $\begin{array}{l}\text { Modera- } \\
\text { damente } \\
\text { alto }\end{array}$ & Agua \\
\hline $\begin{array}{l}\text { Família Prochilodontidae } \\
\text { Prochilodus sp. }\end{array}$ & $\begin{array}{l}2 \\
1\end{array}$ & 30 & $\begin{array}{l}4.7 \pm 0.3 \\
4.2\end{array}$ & $\begin{array}{l}12.5-1.0 \\
17.9\end{array}$ & $\begin{array}{l}\text { Pronun- } \\
\text { ciado }\end{array}$ & -0.79 & Lótico & Lento & Variado & $\begin{array}{l}\text { Epibên- } \\
\text { tico }\end{array}$ & Ativo & $\begin{array}{l}\text { Modera- } \\
\text { damente } \\
\text { lento }\end{array}$ & Agua \\
\hline $\begin{array}{l}\text { Famlíia Curimatidae } \\
\text { Curimatus sp. }\end{array}$ & 1 & 30 & 6.0 & 10.6 & Pequeno & -0.35 & Lótico & Lento & Variado & $\begin{array}{l}\text { Epibên- } \\
\text { tico }\end{array}$ & Ativo & $\begin{array}{l}\text { Modera- } \\
\text { damente } \\
\text { lento }\end{array}$ & Agua \\
\hline $\begin{array}{l}\text { Família Anostomidae } \\
\text { Schizodon sp. }\end{array}$ & $\begin{array}{l}3 \\
1\end{array}$ & 30 & $\begin{array}{l}16.2 \pm 1.2 \\
15.4\end{array}$ & $\begin{array}{l}30.0 \pm 2.1 \\
38.0\end{array}$ & $\begin{array}{l}\text { Mode- } \\
\text { rado }\end{array}$ & -0.49 & Lótico & Rápido & $\begin{array}{l}\text { Centros } \\
\text { riachos }\end{array}$ & Pelágico & $\begin{array}{l}\text { Muito } \\
\text { ativos } \\
\text { nada- } \\
\text { dores }\end{array}$ & $\begin{array}{l}\text { Modera- } \\
\text { damente } \\
\text { alto }\end{array}$ & Agua \\
\hline $\begin{array}{l}\text { Família Hemiodontidae } \\
\text { Hemiodus sp. }\end{array}$ & 1 & 30 & 22.5 & & $\begin{array}{l}\text { Mode- } \\
\text { rado }\end{array}$ & & Lótico & Rápido & $\begin{array}{l}\text { Centros } \\
\text { riachos }\end{array}$ & $\begin{array}{l}\text { Pelá- } \\
\text { gico }\end{array}$ & $\begin{array}{l}\text { Muito } \\
\text { ativos } \\
\text { nada- } \\
\text { dores }\end{array}$ & $\begin{array}{l}\text { Modera- } \\
\text { damente } \\
\text { alto }\end{array}$ & Agua \\
\hline $\begin{array}{l}\text { Subordem Gymnotoidel } \\
\text { Familia Rhamphichthyidae } \\
\text { Sterropygus macrurus }\end{array}$ & 2 & 30 & $6.5 \pm 0.5$ & $15.5 \pm 0.5$ & $\begin{array}{l}\text { Mode- } \\
\text { rado }\end{array}$ & -0.55 & Lótico & Lento & $\begin{array}{l}\text { Margens } \\
\text { de rios e } \\
\text { riachos }\end{array}$ & $\begin{array}{l}\text { Epibên- } \\
\text { tico }\end{array}$ & Ativo & $\begin{array}{l}\text { Mode- } \\
\text { rado }\end{array}$ & Agua \\
\hline
\end{tabular}




\begin{tabular}{|c|c|c|c|c|c|c|c|c|c|c|c|c|c|}
\hline Posiçāo sistemática & $\mathbf{N}+$ & co & $\begin{array}{c}P_{50} \\
(\mathrm{~mm} \mathrm{Hg}) \\
\mathrm{CO}_{2}=0\end{array}$ & $\begin{array}{l}P_{\mathrm{so}_{0}} \text { aparente } \\
(\mathrm{mm} \mathrm{Hg}) \\
\mathrm{CO}_{2}=56 \%\end{array}$ & $\begin{array}{r}\text { Efeito } \\
\text { Root }\end{array}$ & $\begin{array}{c}\text { Efeito } \\
\text { Bohr++ }\end{array}$ & $\begin{array}{l}\text { Habitat } \\
\text { geral }\end{array}$ & $\begin{array}{c}\text { Zona } \\
\text { habitat }\end{array}$ & $\begin{array}{l}\text { Habitat } \\
\text { Especí- } \\
\text { fico }\end{array}$ & $\begin{array}{l}\text { Habitat } \\
\text { vida }\end{array}$ & $\begin{array}{l}\text { Nivel } \\
\text { ativi- } \\
\text { dade }\end{array}$ & $\begin{array}{c}\text { Oxigênio } \\
\text { dissol- } \\
\text { vido }\end{array}$ & $\begin{array}{l}\text { Modo } \\
\text { respi- } \\
\text { ração }\end{array}$ \\
\hline $\begin{array}{l}\text { Subordem Siluroidei } \\
\text { Família Doradidae } \\
\text { Anadoras sp. } \\
\text { Hassar sp. } \\
\text { Pseudodoras sp. }\end{array}$ & $\begin{array}{l}1 \\
2 \\
1\end{array}$ & $\begin{array}{l}30 \\
30 \\
30\end{array}$ & $\begin{array}{l}7.0 \\
9.7 \pm 0.3 \\
11.6\end{array}$ & $\begin{array}{l}10.4 \\
30.0 \pm 1.0 \\
13.5\end{array}$ & Não & $\begin{array}{l}-0.24 \\
-0.21 \\
-0.10\end{array}$ & Lótico & Lento & $\begin{array}{l}\text { Margens } \\
\text { e centros } \\
\text { de rios e } \\
\text { riachos }\end{array}$ & $\begin{array}{l}\text { Bêntico } \\
\text { e Epi- } \\
\text { bêntico }\end{array}$ & Ativo & $\begin{array}{l}\text { Mode- } \\
\text { rado }\end{array}$ & Agua \\
\hline $\begin{array}{c}\text { Familia Auchenipteridae } \\
\text { Auchenipterus sp. }\end{array}$ & 1 & 30 & 10.1 & 30.0 & $\begin{array}{l}\text { Mode- } \\
\text { rado }\end{array}$ & -0.60 & Lótico & Rápido & $\begin{array}{l}\text { Centros } \\
\text { e mar- } \\
\text { gens de } \\
\text { riachos }\end{array}$ & Pelágico & Ativo & $\begin{array}{l}\text { Modera- } \\
\text { damente } \\
\text { Alto }\end{array}$ & Agua \\
\hline $\begin{array}{l}\text { Família Pimelodidae } \\
\text { Brachyplatystoma sp. } \\
\text { Pimelodella sp. } \\
\text { Pimelodus sp. } \\
\text { Pseudoplatystoma sp. } \\
\text { Rhamdia sp. }\end{array}$ & $\begin{array}{l}1 \\
1 \\
1 \\
1 \\
2 \\
1\end{array}$ & $\begin{array}{l}30 \\
30 \\
30 \\
30 \\
30\end{array}$ & $\begin{array}{l}10.7 \\
11.8 \\
9.9 \\
10.6 \\
10.8 \pm 1.0 \\
11.2\end{array}$ & $\begin{array}{l}25.1 \\
18.5 \\
25.0 \\
25.2 \\
16.6 \pm 0.5 \\
16.2\end{array}$ & Não & $\begin{array}{l}-0.59 \\
-0.28 \\
-0.57 \\
-0.53 \\
-0.27 \\
-0.25\end{array}$ & Lótico & Variada & $\begin{array}{l}\text { Centro } \\
\text { e mar- } \\
\text { gens de } \\
\text { riachos }\end{array}$ & $\begin{array}{l}\text { Pelágico } \\
\text { e Epi- } \\
\text { bêntico }\end{array}$ & $\begin{array}{l}\text { Ativo c/ } \\
\text { natação } \\
\text { mode- } \\
\text { rada }\end{array}$ & $\begin{array}{l}\text { Mode- } \\
\text { rada- } \\
\text { mente } \\
\text { alto }\end{array}$ & Agua \\
\hline $\begin{array}{l}\text { Familia Ageneiosidae } \\
\text { Ageneiosus sp. }\end{array}$ & 2 & 30 & $10.0 \pm 0.2$ & $16.8 \pm 0.6$ & Não & -0.30 & Lótico & Rápida & $\begin{array}{l}\text { Margens } \\
\text { rios }\end{array}$ & Pelágico & Ativo & $\begin{array}{l}\text { Modera- } \\
\text { damente } \\
\text { alto }\end{array}$ & Agua \\
\hline $\begin{array}{l}\text { Familia Hypophthalmidae } \\
\text { Hypophthalmus sp. }\end{array}$ & 1 & 30 & 10.8 & 18.5 & Não & -0.31 & Lótico & Rápida & $\begin{array}{l}\text { Margens } \\
\text { rios }\end{array}$ & Pelágico & Ativo & $\begin{array}{l}\text { Modera- } \\
\text { damente } \\
\text { alto }\end{array}$ & Agua \\
\hline $\begin{array}{l}\text { Familia Callichthydae } \\
\text { Hoplosternum littorale }\end{array}$ & 3 & 30 & $9.5 \pm 0.9$ & $17.8 \pm 0.2$ & Não & -0.33 & Lótico & $\begin{array}{l}\text { Lenta e } \\
\text { litoral }\end{array}$ & $\begin{array}{l}\text { Lagos } \\
\text { peque- } \\
\text { nos e } \\
\text { pântanos }\end{array}$ & Bêntico & $\begin{array}{l}\text { Movi- } \\
\text { mento } \\
\text { acima } \\
\text { da terra }\end{array}$ & $\begin{array}{l}\text { Modera- } \\
\text { damente } \\
\text { baixo }\end{array}$ & $\mathrm{Ar}$ \\
\hline
\end{tabular}




\begin{tabular}{|c|c|c|c|c|c|c|c|c|c|c|c|c|c|}
\hline Posição sistemática & $\mathbf{N}+$ & co & $\begin{array}{c}P_{50} \\
(\mathrm{~mm} \mathrm{Hg}) \\
\mathrm{CO}_{2}=0\end{array}$ & $\begin{array}{c}P_{s_{0}} \text { oporente } \\
(\mathrm{mm} \mathrm{Hg}) \\
\mathrm{CO}_{2}=56 \%\end{array}$ & $\begin{array}{l}\text { Efeito } \\
\text { Root }\end{array}$ & $\begin{array}{c}\text { Fator } \\
\text { Bohr }++\end{array}$ & $\begin{array}{l}\text { Habitat } \\
\text { geral }\end{array}$ & $\begin{array}{c}\text { Zona } \\
\text { habitat }\end{array}$ & $\begin{array}{l}\text { Habitat } \\
\text { Especi- } \\
\text { fico }\end{array}$ & $\begin{array}{l}\text { Habitat } \\
\text { vida }\end{array}$ & $\begin{array}{l}\text { Nivel } \\
\text { ativi- } \\
\text { dade }\end{array}$ & $\begin{array}{l}\text { Oxigênio } \\
\text { dissol- } \\
\text { vido }\end{array}$ & $\begin{array}{l}\text { Modo } \\
\text { respi- } \\
\text { ração }\end{array}$ \\
\hline $\begin{array}{l}\text { Familia Loricariidae } \\
\text { Ancistrus sp. } \\
\text { Ancestrinae, unidentified sp. } \\
\text { Loricaria sp. } \\
\text { Parahemiodon sp. } \\
\text { Hypostomus sp. } \\
\text { Pterygoplichthys sp. }\end{array}$ & $\begin{array}{l}3 \\
1 \\
1 \\
1 \\
3 \\
4 \\
4\end{array}$ & $\begin{array}{l}30 \\
30 \\
30 \\
30 \\
30 \\
20 \\
30\end{array}$ & $\begin{array}{l}9.6 \pm 0.2 \\
14.3 \\
9.8 \\
7.5 \\
18 . \pm 1.3 \\
2.4 \pm 0.1 \\
10.8 \pm 0.3\end{array}$ & $\begin{array}{l}13.2 \pm 0.2 \\
- \\
17.0 \\
9.5 \\
24.1 \pm 2.1 \\
9.7 \pm 0.2 \\
13.5 \pm 0.1\end{array}$ & Nāo & $\begin{array}{l}-0.18 \\
-0.30 \\
-0.13 \\
-0.16 \\
-0.12\end{array}$ & $\begin{array}{l}\text { Lótico e } \\
\text { Lêntico }\end{array}$ & Lento & $\begin{array}{l}\text { Margens } \\
\text { riachos }\end{array}$ & $\begin{array}{l}\text { Bêntico } \\
\text { e Epi- } \\
\text { bêntico }\end{array}$ & $\begin{array}{l}\text { Nada- } \\
\text { dores } \\
\text { lentos }\end{array}$ & $\begin{array}{l}\text { Modera- } \\
\text { mente } \\
\text { baixo }\end{array}$ & $\begin{array}{l}\text { Alguns } \\
\text { bimo- } \\
\text { dais }\end{array}$ \\
\hline $\begin{array}{l}\text { Superordem Atherinomorpha } \\
\text { Ordem Atheriniformes } \\
\text { Familia Belonidae } \\
\text { Potamorrhaphis sp. }\end{array}$ & $\begin{array}{l}1 \\
2\end{array}$ & $\begin{array}{l}20 \\
30\end{array}$ & $\overline{-}$ & $\begin{array}{l}22.0 \\
49.0 \pm 3.0\end{array}$ & - & - & Lótico & Rápido & $\begin{array}{l}\text { Riachos } \\
\text { e cen- } \\
\text { tros de } \\
\text { rios }\end{array}$ & $\begin{array}{l}\text { Pelágico } \\
\text { e neus- } \\
\text { tônico }\end{array}$ & $\begin{array}{l}\text { Nadador } \\
\text { muito } \\
\text { ativo }\end{array}$ & Alta & Agua \\
\hline $\begin{array}{l}\text { Superordem Acanthopterygi } \\
\text { Ordem Synbranchiformes } \\
\text { Familia Synbranchidae } \\
\text { Synbranchus marmoratus }\end{array}$ & $\begin{array}{l}6 \\
6\end{array}$ & $\begin{array}{l}20 \\
30\end{array}$ & $\begin{array}{l}2.7 \pm 0.2 \\
9.4 \pm 0.6\end{array}$ & $\begin{array}{r}6.2 \pm 0.5 \\
11.3 \pm 0.1\end{array}$ & Não & $\begin{array}{l}-0.45 \\
-0.31\end{array}$ & Lêntico & Litoral & $\begin{array}{l}\text { Charcos } \\
\text { e pân- } \\
\text { tanos }\end{array}$ & Bêntico & $\begin{array}{l}\text { Lentos e } \\
\text { algumas } \\
\text { vezes es } \\
\text { tivado }\end{array}$ & $\begin{array}{l}\text { Muito } \\
\text { baixo a } \\
\text { modera- } \\
\text { damente } \\
\text { baixo }\end{array}$ & Bimodial \\
\hline $\begin{array}{l}\text { Ordem Perciformes } \\
\text { Subordem Percoidei } \\
\text { Familia Cichlidae } \\
\text { Acaronia nassa } \\
\text { Astronotus occellatus } \\
\text { Chaetobranchopsis orbicu- } \\
\text { laris } \\
\text { Cichlasoma severum } \\
\text { Geophagus surinamensis }\end{array}$ & $\begin{array}{l}2 \\
1 \\
2 \\
2 \\
2\end{array}$ & $\begin{array}{l}30 \\
30 \\
30 \\
30 \\
30\end{array}$ & $\begin{array}{l}5.7 \pm 0.2 \\
9.8 \\
4.2 \pm 0.1 \\
7.5 \pm 0.1 \\
5.0 \pm 0.4\end{array}$ & $\begin{array}{l}13.0 \pm 0.9 \\
13.7 \\
13.0 \pm 0.5 \\
15.0 \pm 2.0 \\
18.5 \pm 0.7\end{array}$ & $\begin{array}{l}\text { Mode- } \\
\text { rado }\end{array}$ & $\begin{array}{l}\text { Mode- } \\
\text { rado a } \\
\text { alto }\end{array}$ & $\begin{array}{l}\text { Lêntico } \\
\text { e } \\
\text { Lótico }\end{array}$ & Litoral & $\begin{array}{l}\text { Lagos } \\
\text { peque- } \\
\text { nos e } \\
\text { margens } \\
\text { riachos }\end{array}$ & $\begin{array}{l}\text { Pelágico } \\
\text { e Epi- } \\
\text { bêntico }\end{array}$ & $\begin{array}{l}\text { Nadado- } \\
\text { res len- } \\
\text { tos so- } \\
\text { bre su- } \\
\text { bstrato }\end{array}$ & $\begin{array}{l}\text { Mode- } \\
\text { rado a } \\
\text { lento }\end{array}$ & Agua \\
\hline
\end{tabular}


(1) $\mathrm{P}_{50}=10,8 \mathrm{~mm} \mathrm{Hg}$ a $\left.\mathrm{pH} 7,6, \mathrm{I}^{\cap}\right) \Delta \log$ $\mathrm{P}_{50} / \Delta \mathrm{pH}=-0,234$ e $\left({ }^{3}\right)$ sem efeito Root a $23^{\circ} \mathrm{C}$. Ademais, a análise do hemolisado e da hemoglobina fracionada de Lepidosiren são dados por Phelps et al. (1978) .

Duas espécies de peixes de língua óssea foram estudadas, o Osteoglossum bicirrhosum de respiração aquática e Arapaima gigas de respiração aérea obrigatória (Fig. 4 e 5). O sangue de Osteoglossum tem uma afinidade de oxigênio aparente $\left(P_{50}\right.$ Aparente $)$ maior que o Arapaima a $30^{\circ} \mathrm{C}$ ambos na ausência e presença de $5,6 \% \mathrm{CO}_{2}$ (Tabela I).

O sangue de Arapaima aparentemente não tem efeito Root, enquanto que o Osteoglossum tem sólido efeito Root quando o $\mathrm{pH}$ do sangue $<6,8$. Este par de peixes de respiração aquática Osteoglossum e de respiração aérea Arapaima ilustra dados consistentes com a hipótese de Johansen \& Lenfant (1972), de que os sangues de respiração aérea têm mais baixa afinidade que os de respiração branquial. No entanto, quando o oxigênio começa a diminuir na massa de água o Osteoglossum utiliza a camada de água da superfície mais oxigenada. Ambos os sangues de Osteoglossum e de Arapaima, são similares e um efeito Bohr relativamente pronunciado $(-0,60 \mathrm{e}-0,57$ respectivamente) o qual não é coerente com a noção de que o efeito Bohr diminui para os de respiração aquática (Carter, 1957).

TABELA II - Quantidade de oxigênio dissolvido e dióxido de carbono para três habitat espeeífico de acordo ao trabalho de Carter de Willmer (1934)

\begin{tabular}{l|c|c|c|c}
\hline $\begin{array}{c}\text { Habitat } \\
\text { Geral }\end{array}$ & $\begin{array}{c}\text { Zona } \\
\text { Habitat }\end{array}$ & $\begin{array}{c}\text { Habitat } \\
\text { Específico }\end{array}$ & $\begin{array}{c}\text { Oxigênio } \\
\text { Dissol- } \\
\text { vido } \\
\text { mm Hg }\end{array}$ & $\begin{array}{c}\mathrm{CO}_{2} \text { Dis- } \\
\text { solvido } \\
\text { mm Hg }\end{array}$ \\
\hline \multirow{2}{*}{ Lótico } & Rápido & Rios * & $120-135$ & $2-5$ \\
\cline { 2 - 5 } & Lento & Riachos & $69-45$ & $6-22$ \\
\hline Lêntico & Litoral & Pantanos & $5-55$ & $16-32$ \\
\hline
\end{tabular}

(*) $\mathrm{CO}_{2}$ pode alcançar $18 \mathrm{~mm} \mathrm{Hg}$ durante a época de chuvo.
O sangue de três caracídeos (família Characidae) foram estudados: Mylossoma, Serrasalmus e Triportheus. As trés espécies têm valores de $\mathrm{P}_{50}$ similares quando está ausente o

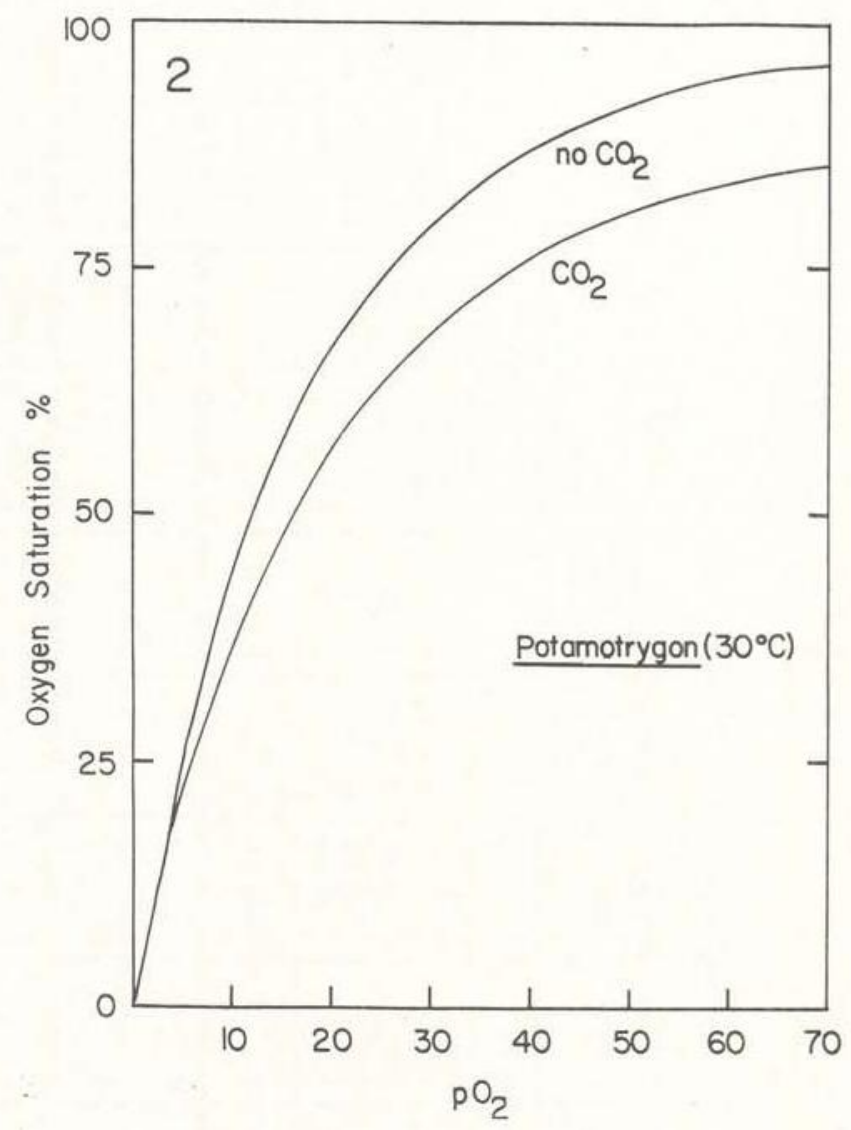

Fig. 2-38 - Curva de equilíbrio de oxigênio de sangue total de representantes individuais de vários peixes da Amazônia sob diferentes condições experimentais. Descreve-se nas ordenadas a porcentagem de saturação de hemoglobina pelo oxigênio (ou onde corresponde a porcentagem de saturação aparente) enquanto que a abscissa indica a pressão parcial de oxigênio $\left(\mathrm{pO}_{2}\right) \mathrm{em} \mathrm{mm} \mathrm{Hg}$. Quando o $\mathrm{CO}_{2}$ não está no equulibrio de gases as curvas são marcadas "não $\mathrm{CO}_{2}$ ". Se o $\mathrm{CO}_{2}$ estava presente no equilíbrịo de gases c o efeito Root näo foi detectável é empregado o símbolo " $\mathrm{CO}_{2}$ ". Quando o $\mathrm{CO}_{2}$ estava presente e o $\in$ feito Root foi detectado. Então o símbolo " $\mathrm{CO}_{2}+$ " foi usado e a porcentagem de saturação de oxigênio poderia, por conseguinte, ser uma oxigenação aparente. As curvas tem sido corrigidas no sentido de efeito Root (ver método) e estão representadas pelo símbolo " $\mathrm{CO}_{2}$ ". As temperaturas e espécies são indicadas oportunamente nas figuras apropriadas.

(3) - Como estes animais não são analisados a $5.6 \%$ de $\mathrm{CO}_{2}$ ambiental, somente dados obtidos na ausêncla de $\mathrm{CO}_{2}$ são usados para interpretar estudos comparativos, tais dados poderiam refletir mais aproximadamente a união de oxigênio dos organismos na interfase do meio ambiente (guelra e outros órgãos de respiração). 
$\mathrm{CO}_{2}$ no equilíbrio de gases (com o pH do sangue $>7,6$ ). O sangue de Mylossoma e Serrasalmus têm afinidade pelo oxigênio similar $\left(P_{50}\right.$ Aparente) quando $5,6 \% \quad \mathrm{CO}_{2}$ estão presentes no gás. Embora ambos os sangues revelem um substancial efeito Root na preseneça de $\mathrm{CO}_{2}(\mathrm{pH} 6,6)$, que o Mylossoma que tem um pronunciado efeito (ver Fig. 6 e 7). Ante valores de $\mathrm{pH}$ mais altos, $(\mathrm{pH} 7,0$ e 8,0$)$ o sangue de Mylossoma e Serrasalmus tem similar efeito Bohr aparente $(-0,39$ e $-0,38$ respectivamente). $\mathrm{O}$ efeito dado para Triportheus é o resultado de um único experimento. As curvas de equilíbrio de oxigênio do sangue de cada um dos três caracídeos são similares em ambas na forma e feito do $\mathrm{CO}_{2}$ (Figs. 6 e 8) $\left({ }^{4}\right)$.

Dos peixes caracoídes da família Erythrinidae foram estudados, o Hoplias malabaricus de respiração aquática e o Hoplerythrinus unitaeniatus de respiração aérea facultativa. A $30^{\circ} \mathrm{C}$, o valor de $P_{50}$ do sangue é $11,4 \mathrm{~mm} \mathrm{Hg}$, enquanto que o $\mathrm{P}_{50}$ do Hoplias é $4,8 \mathrm{~mm} \mathrm{Hg}$. Isto é consistente com a hipótese de que há uma mais alta afinidade pelo oxigênio nos de respiração aquática comparados com os de respiração aérea (Johansen e Lenfant, 1972); na presença de $5,6 \% \mathrm{CO}_{2}, 0 \mathrm{pH}$ do sangue de Hoplias foi mais baixo que 6,7 . Na faixa deste $\mathrm{pH}$, o sangue apresenta efeito Root.

Este parecer é compatível com o de Willmer (1934) que também encontrou efeito Root para Hoplias na presença do $\mathrm{CO}_{2}$. Em faixa de $\mathrm{pH}$, altos, não há efeito Root e é evidente o fator Bohr; para o sangue de Hoplias foi 0,48 . O sangue de Hoplerythrinus tem uma diferença leve de efeito Bohr nas duas temperaturas estudadas. A $30^{\circ} \mathrm{C}$, o fator Bohr para o sangue de Hoplias foi $-0,75$, enquanto que a $20^{\circ} \mathrm{C}$ este foi $-0,63$. A figura 10 ilustra a curva de equilíbrio de sangue de Hoplerythrinus a ambas as temperaturas $20^{\circ} \mathrm{C}$ e $30^{\circ} \mathrm{C}$, na presença e ausência de $\mathrm{CO}_{2}$. A afinidade de oxigênio do sangue de Hoplerythrinus tem uma significativa sensibilidade térmica. Ademais, a análise do hemolisado destes peixes são dados por Riggs et al. (1978).
Rhaphiodon vulpinus, (família Cynodontidae) é um hábil nadador e encontra-se em águas de correnteza. Quando o $\mathrm{CO}_{2}$ não está presente no equilíbrio de gases o $P_{50}(10,7 \mathrm{~mm}$ $\mathrm{Hg}, 30^{\circ} \mathrm{C}$ ) destas espécies é similar ao dos peixes que vivem em águas moderadamente oxigenadas. $\mathrm{Na}$ presença de $5,6 \% \mathrm{CO}_{2} \circ \mathrm{P}_{50}$ Aparente incrementa a $38,1 \mathrm{~mm} \mathrm{Hg}\left({ }^{4}\right)$. A Figura 11 ilustra a curva de equilíbrio de oxigênio de ambos na presença e ausência de $\mathrm{CO}_{2}$. O sangue de Raphiodon apresenta um pronunciado efeito Root quando $\mathrm{o} \mathrm{CO}_{2}$ está presente no gás $\left({ }^{4}\right)$.

O sangue de Prochilodus (família Prochilodontidae) tem uma alta afinidade pelo oxigênio na ausência de $\mathrm{CO}_{2}$ (Tabela I). Esta alta afinidade pelo oxigênio é compatível com sua existência epibêntica e extensa distribuição. Quando $5,6 \%$ de $\mathrm{CO}_{2}$ estão presentes no equilíbrio de gases, o $\mathrm{P}_{50}$ Aparente, aumenta sensivelmente. Ademais, só um pequeno efeito Root foi detectado no sangue a $\mathrm{pH} 7,1$, um pronunciado efeito Root foi evidente a $\mathrm{pH}$ baixo $(\mathrm{pH}$ $6,6)$. A Figura 12 apresenta a curva de equilíbrio para o sangue de Prochilodus com 5,6\% e sem $\mathrm{CO}_{2}$. Esta figura demonstra que quando o $\mathrm{CO}_{2}$ não está presente, $90 \%$ do sangue está oxigenado a $\mathrm{pO}_{2}=22 \mathrm{~mm} \mathrm{Hg}$. Esta espécie parece a mais condicionada a sobreviver em águas com hipoxia relativa. Não é de surpreender que Prochilodus possa ser encontrada numa ampla variedade de habitat (Fink \& Fink, 1978) .

Curimatus tem sangue com alta afinidade $\left(P_{50}=6,0 \mathrm{~mm} \mathrm{Hg}\right.$ ) e moderado efeito Bohr $(-0,35)$ e pequeno e moderado efeito Root. As curvas de equilíbrio de oxigênio são apresentadas na Fig. 13.

O sangue de Schizodon (família Anostomidae) apresenta baixa afinidade pelo oxigênio na ausência de $\mathrm{CO}_{2}$ (Fig. 14) e, além disso, uma redução quando $5,6 \% \mathrm{CO}_{2}$ estão presentes no equilíbrio de gases (Tabela I) $\left({ }^{4}\right)$. Esta diminuição de afinidade de oxigênio sugere que Schizodon não pode sobreviver em águas de baixo conteúdo de oxigênio. De fato, a presença de $\mathrm{CO}_{2}$ nas águas de baixo índice de oxige-

\footnotetext{
(4) - O sangue de peixes com pronunciado efeito Root (Tabela I) poderia provavelmente ter um elevado $P_{50} e$ efeito Bohr a pH mais baixos do que os exemplificados por nossos dados de afinidade de oxigênio observada $\left(P_{50}\right.$ Aparente) e efeito Bohr aparente (Tabela I).
} 

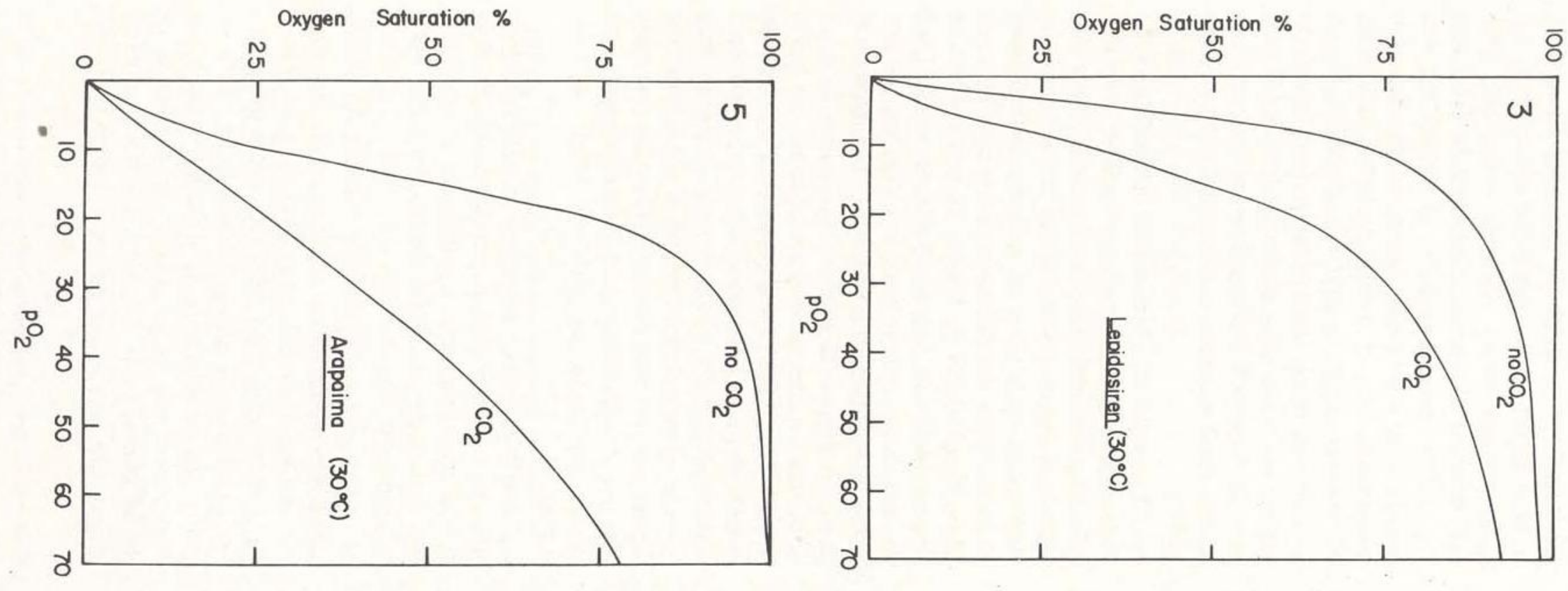

Apparent
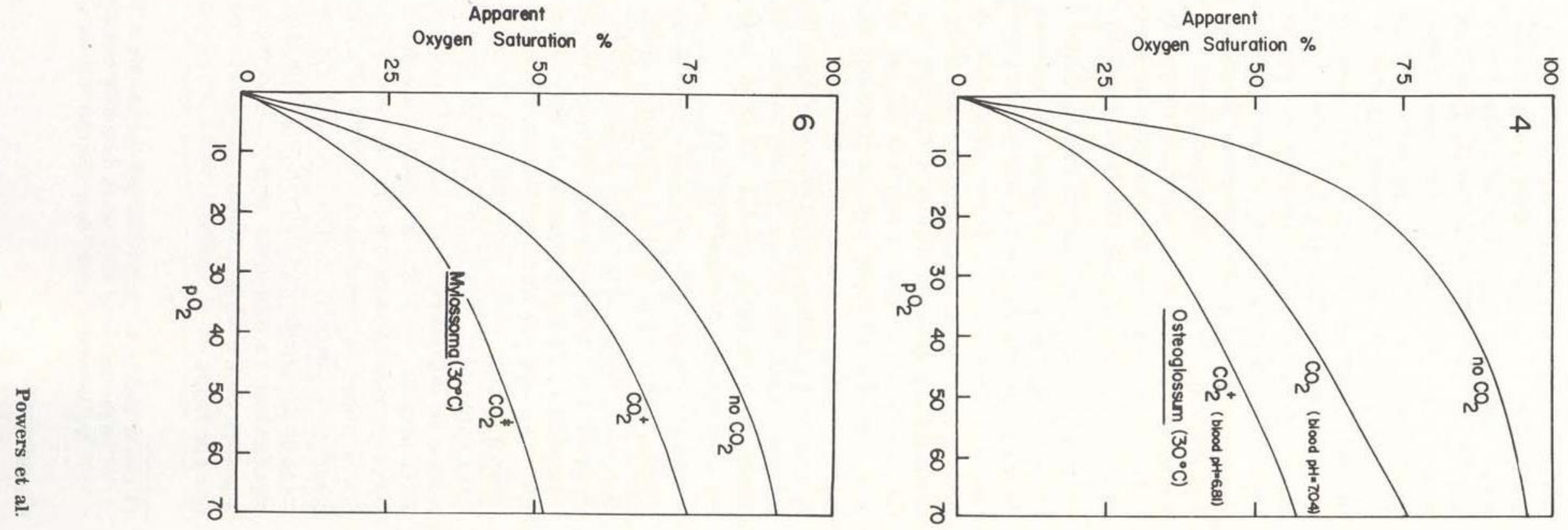


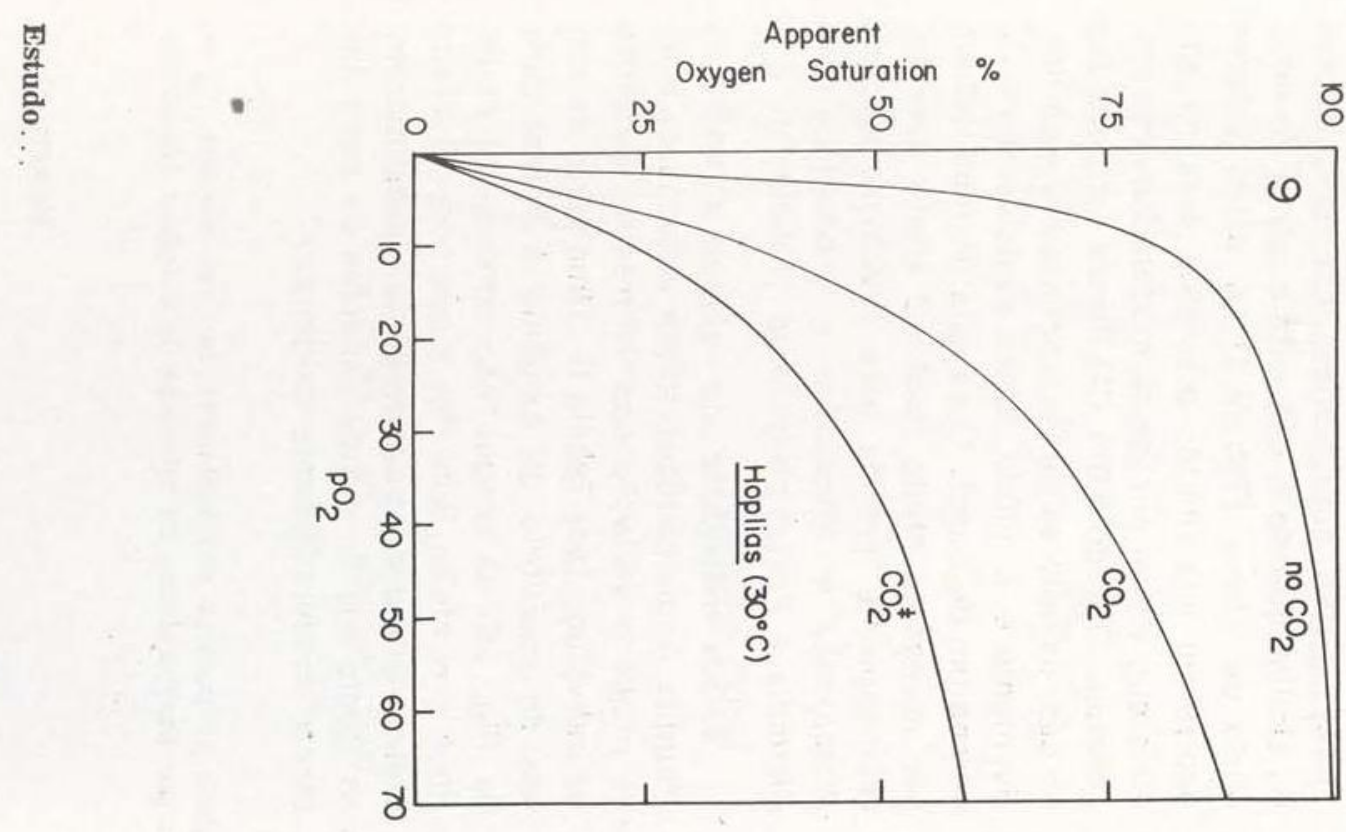

Apparent

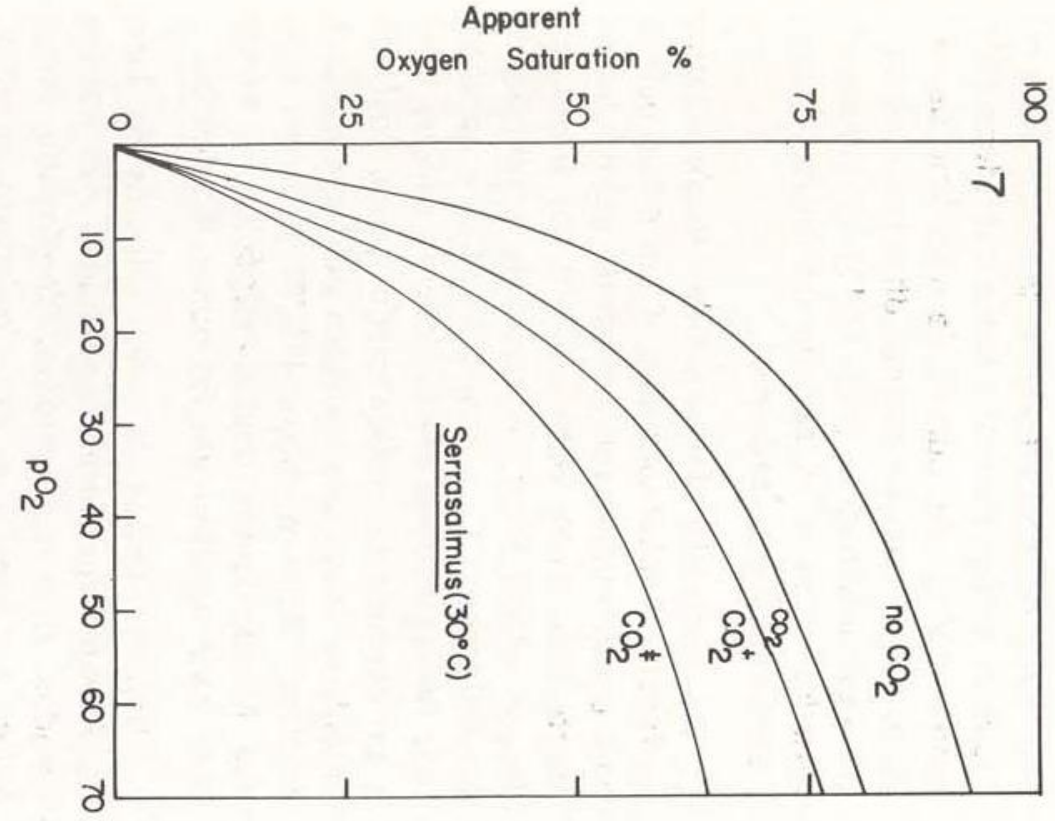

Apparent
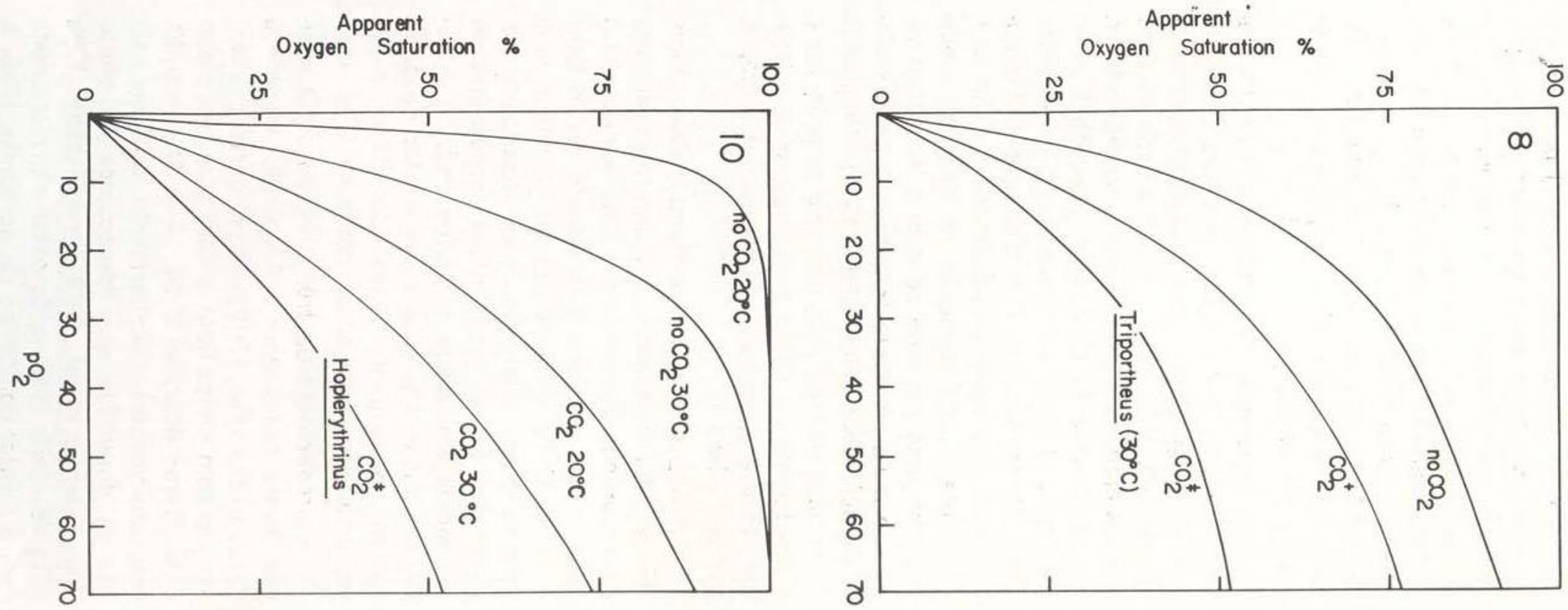
nação nos trópicos (ver Tabela II) poderia provavelmente limitar estas espécies e, em parte, reduzir moderadamente a oxigenação das águas. Não é de surpreender que o Schizodon é encontrado no centro da correnteza dos rios altamente oxigenados (Tabela I); na presença de $5,6 \%$ de $\mathrm{CO}_{2}$ o sangue de Schizodon demonstrou um relativo e pronunciado efeito Root a pH baixo ( $\left.{ }^{4}\right)$.

Um espécime de Hemiodus (família Hemiodontidae) foi estudado. A curva de equilibrio de oxigênio foi determinada só na ausência de $\mathrm{CO}_{2}$ (Fig. 15) e não é sabido se este sangue apresenta efeito Root e/ou efeito Bohr. No hemolisado de Hemiodus. No entanto, Farmer et al. (1978) encontraram um forte efeito Root. $\mathrm{Na}$ ausência de $\mathrm{CO}_{2}$, o sangue de Hemiodus tem mais baixa afinidade que o Schizodon e a curva é mais sigmoidal. A baixa afinidade pelo oxigênio consistente com a alta oxigenação do meio ambiente frequentado por Hemiodus e Schizodon (Fink \& Fink, 1978). Hemiodus é um hábil nadador que usa uma natação veloz e movimento de saltos para escapar do predador. Este é encontrado no centro dos igarapés e rios (Tabela I).

Sternopygus macrurus (família Rhamphichthyidae) foi examinado como um representante da subordem Gymnotoidei. Esta espécie tem sangue com pequeno e moderado efeito Bohr e Root. $O P_{50}$ na ausência de $\mathrm{O}_{2}$ indica uma relativa e alta afinidade como poderíamos esperar em peixes epibênticos, especialmente em meios ambientes sombrios onde, o material em suspensão está acompanhado de diminuição de oxigênio dissolvido. Uma curva representativa está apresentada na (Fig. 16).

Represetantes de três gêneros de Doradidae foram examinados: Anadoras, Hassar e Pseudodoras (Fig. 17-19). Estes doradides têm sangue sem efeito Root e com pequeno efeito Bohr (fator Bohr, - 0,24, - 0,21, - 0,40, respectivamente). Similarmente, os hemolisados de doradides são desprovidos de efeito Root (Farmer et al., 1978 em emissão). Esta falta de efeito Root pode estar correlacionada com o habitat epibêntico de doradides (Fink \&
Fink, 1978, em preparação) e, em geral, pela redução de bexiga natatória entre silurídeos (Alexander, 1965). As curvas de equilíbrio de oxigênio foram completamente diferentes no sangue destas espécies (Fig. 17-19) de alguns resultados obtidos no sangue de outros peixes sistematicamente próximos.

Ao contrário do doradide, Auchenipterus da família Auchenipteridae, é um peixe pelágico e o seu sangue tem um efeito Bohr relativamente alto (Fator Bohr $=-0,60$ ) e um moderado efeito Root. A curva de equilíbrio de oxigênio sem $\mathrm{CO}_{2}$ e com $5,6 \% \mathrm{CO}_{2}$ é apresentado na Fig. 20. O efeito Bohr do sangue total é provavelmente influenciado pelos fosfatos orgânicos como são também pelo pH intraeritrócitos; Bunn e Riggs (1978) notaram que, nas hemoglobinas destas espécies, o efeito Bohr está ausente até no ponto isoelétrico.

Representantes de cinco gêneros da famílía Pimelodidae foram analisados em nossos estudos: Brachyplatystoma, Pimelodella, Pimelodus e Rhamdia e Pseudoplatystoma, (Fig. 21-24). Estes pimelodides têm sangue com $\mathrm{P}_{50}$ similar quando o $\mathrm{CO}_{2}$ está ausente do equilíbrio de gases (Tabela I), e estes valores ocorreram nos limites previstos para os animais que vivem em águas moderadamente oxigenadas. Quando $5,6 \% \mathrm{CO}_{2}$ foram introduzidos no gás, os valores de $P_{50}$ aumentaram significativamente e, a miúdo, foram decisivamente di. versos um do outro. $O$ sangue de pimelodides não apresenta efeito Root. O efeito Bohr foi relativamente grande para Brachyplatystoma, Pimelodella e Pimelodus e moderado para Rhamdia e Pseudoplatystoma (Tabela I) .

Vários indivíduos do gênero Ageneiosus (família Ageneiosidae) foram estudados. Houve pequena variação nos valores de $P_{50}$ entre os indivíduos (ver Tabela I). Uma série de curvas de equilíbrio de oxigênio é apresentada na Fig. 25. O sangue não apresentou eteito Root $\mathrm{e}$ o efeito Bohr foi moderado. O efeito Bohr e afinidade pelo oxigênio apresentaramse iguais aos de outras espécies de meio ambiente moderadamente oxigenado.

(4) - O sangue de peixes com pronunciado efeito Root (Tabela I) poderia provavelmente ter um elevado $P_{50} e$ efeito Bohr a pH mais baixos do que os exemplificados por nossos dados de afinidade de oxigênio observada $\left(P_{50}\right.$ Aparente) e efeito Bohr aparente (Tabela I). 

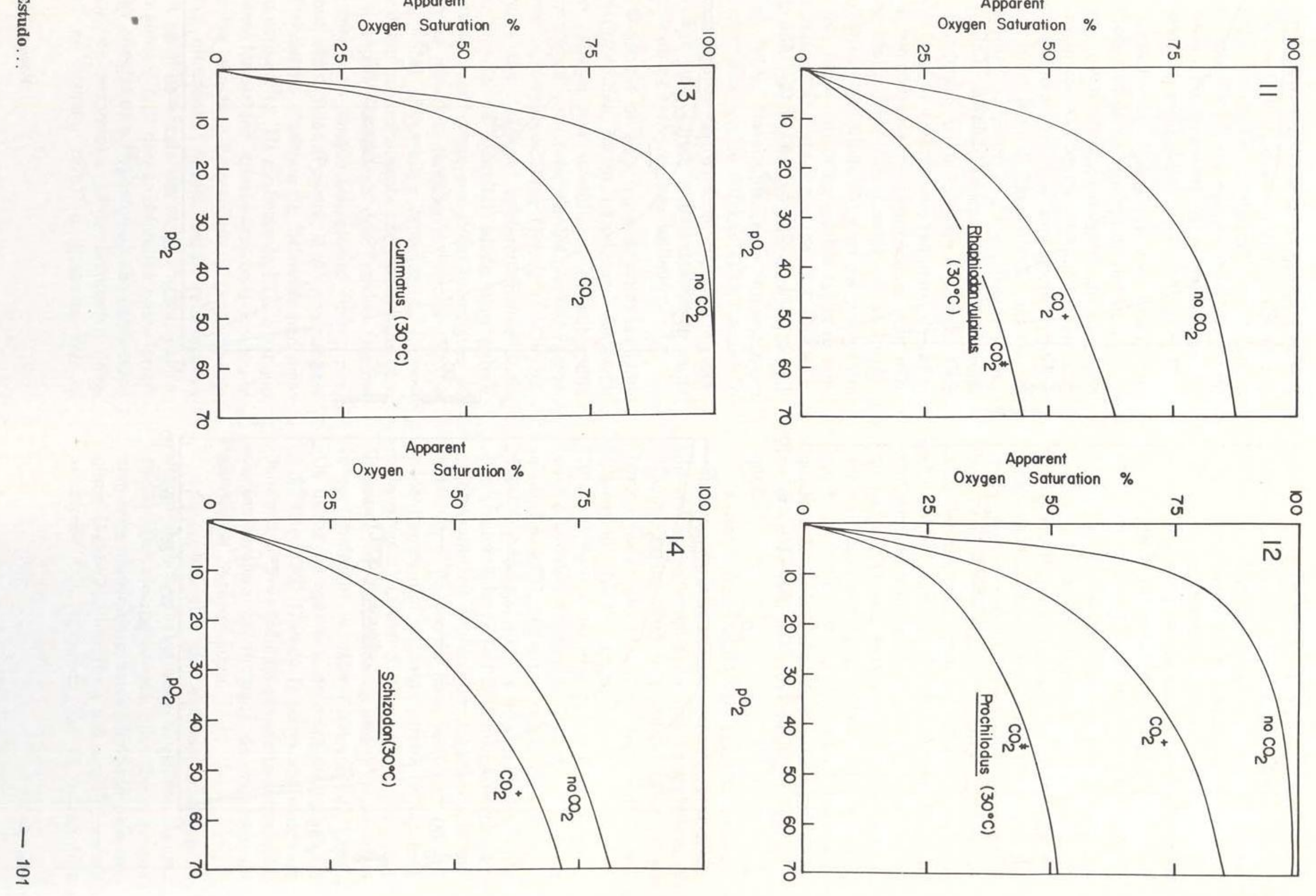

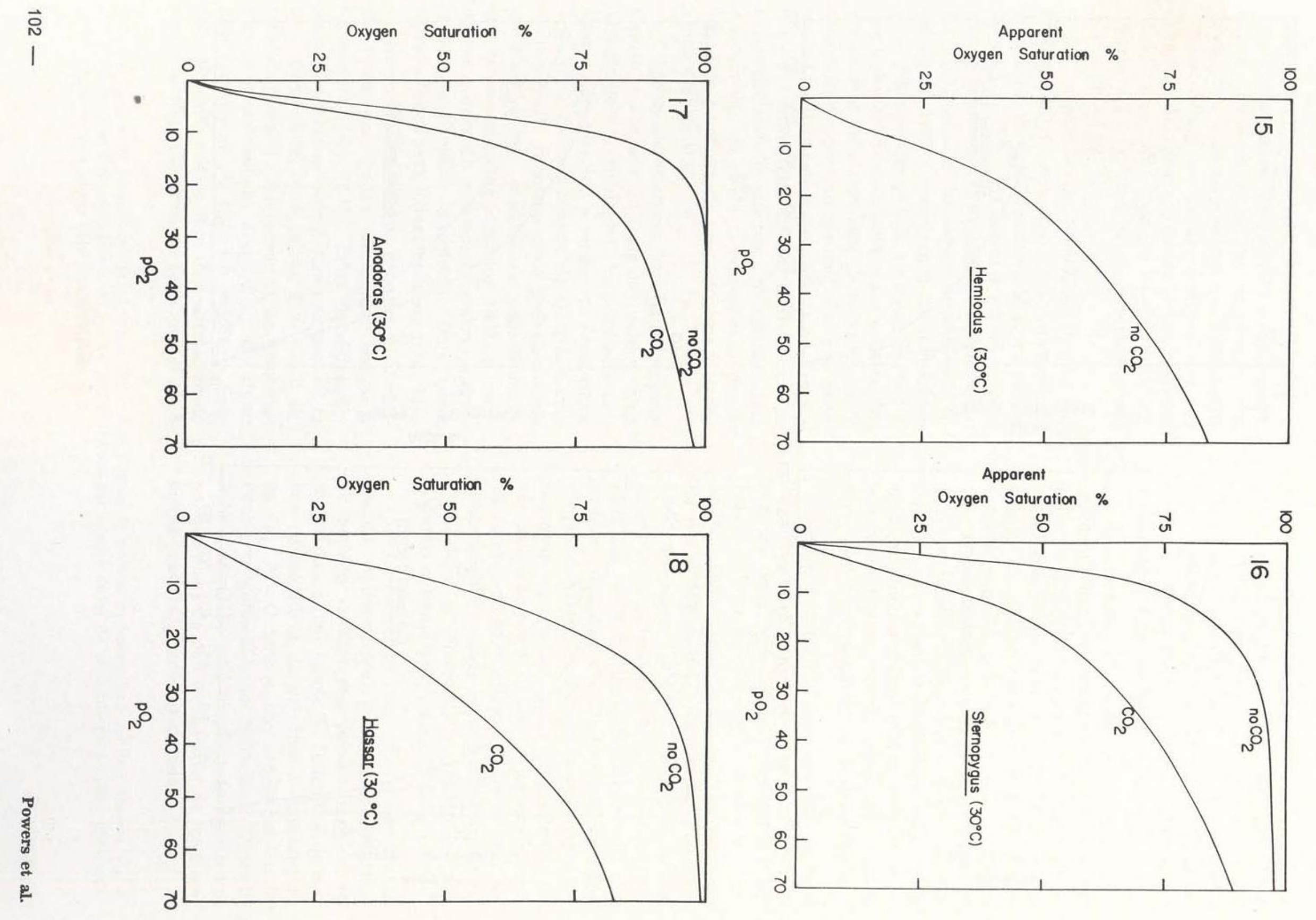
A curva de equilíbrio de oxigênio de sanque de Hypophthalmus (família Hypophthalmidae) produziu resultados similares aos descritos acima sobre o gênero Ageneiosus. Não houve um efeito Root aparente e o efeito Bohr foi moderado (Factor Bohr $=-0,31$ ) .

Hoplosternum littorale é uma espécie de respiração aérea obrigatória da família Callichthyidae, o equilibrio de oxigênio do sangue e não se apresenta com características particulalares, embora estudos associados (Garlick et al., 1978; Bunn \& Riggs, 1978) usando hemoglobina, indiquem uma compensação molecular. Por exemplo, encontramos um efeito Bohr moderado $(-0.33)$ para o sangue. Este efeito Bohr, no entanto, é o resultado do efeito de 2 componentes de hemoglobina com diferente efeito Bohr (ver Garlick et al. 1978). Não detectamos efeito Root no sangue, porém estudos feitos em componentes isolados indiram um componente que tem efeito Root, enquanto que os outros não o têm (Garlick et al. 1978). Nossos dados no Hoplosternum são similares aos de Willmer (1934) exceto o fato de que os valores do $\mathrm{pH}$ do sangue medidos por nós, foram substancialmente mais altos que os referidos por Willmer.

O sangue de seis representantes da familia Loricariidae foram estudados: Ancistrus uma espécie não identificada da subfamília Ancestrinae, Loricaria, Parahemiodon, Hypostomus e Pterygoplichthys (Tabela I). Os loricarides são "catfish" preferentemente sugador, através de aparelho usado para extrair algas etc. de rochas e outras superfícies do leito de igarapés, tanques e charcos (Fink \& Fink, 1978). Em muitos aspectos, os loricarides estão ecologicamente correlacionados com as espécies Catostomid dos Estados Unidos. No entanto, o sangue Catastomid difere, mos. trando efeito Root (Powers, D.A. não publicado) enquanto o sangue de loricaride não mostrou este efeito. $\mathrm{Na}$ ausência de $\mathrm{CO}_{2}$, o sangue destes loricarides apresentou uma moderada e baixa afinidade pelo oxigênio (Fig. 28-31). Estas afinidades podem estar relacionadas com a habilidade de um acessório de respiração aérea o qual parece difundido entre loricarides". Ancistrus e Hypostomus são conhecidos como de respiração aérea facultativa (Kramer e Grahan, 1976) e notamos que a loricaria e Pterygoplichthys não são atingidos desfavoravelmente por uma emersão de várias horas (observação pessoal). Possivelmente, outros loricarides usam acessórios de respiração aérea sob condições hipóxicas. A afinidade pelo oxigênio relativamente baixa e a baixa sensibilidade de loricarides ao $\mathrm{CO}_{2}$ coincidem com uma respiração bimodal destes peixes.

O sangue de Potamorrphaphis (família Belonidae) foi estudado em duas temperaturas $\left(20^{\circ} \mathrm{C}\right.$ e $\left.30^{\circ} \mathrm{C}\right)$ na presença de $5,6 \% \mathrm{CO}_{2}$. A curva de equilíbrio de oxigênio (Fig. 32) demonstrou um significativo efeito de temperatura. No hemolisado de Potamorrhaphis, tem sido demonstrado um pronunciado efeito Root (Farmer et al., 1978, em publicação) e se isto também se aplicasse ao sangue total, o $\mathrm{P}_{50}$ quando $\circ \mathrm{CO}_{2}$ não está presente não poderia ser estimado por nossos dados. No entanto, um $\mathrm{P}_{50}$ Aparente de $49 \mathrm{~mm} \mathrm{Hg}$ e $30^{\circ} \mathrm{C}$, na presença de $5,6 \% \mathrm{CO}_{2}$ indica que o sangue destas espécies tem uma baixa afinidade pelo oxigênio.

Synbranchus marmoratus (família Synbranchidae, da ordem Synbranchiformes) é capaz de ambas as respirações aérea e branquial (Taylor, 1913; Johansen, 1966, 1970) e libera a respiração aérea em água em hipoxia (Johansen, 1970). Encontramos a pH 7,7, $30^{\circ} \mathrm{C}$ um $\mathrm{P}_{50} 9,4 \mathrm{~mm} \mathrm{Hg} \pm 0,6$ (Figura 33) o qual é consistente com um $\mathrm{P}_{50}$ de $7,2 \mathrm{~mm} \mathrm{Hg}$ a $\mathrm{pH} 7,6,25^{\circ} \mathrm{C}$, conforme relato de Johansen (1970). Ademais, o efeito Bohr encontrado por nós (factor Bohr de $-0,31$ ) foi essencialmente o mesmo, de acordo com Johansen (1970). Finalmente, de acordo com Johansen (1970), encontramos um evidente efeito Root, para este sangue. O efeito Root não parece estar presente no hemolisado de ambos os Synbran. chus (Phelps et al. 1978, Farmer et al. 1978). Os dados do equilíbrio do oxigênio do sangue a $20^{\circ} \mathrm{C}$ e $30^{\circ} \mathrm{C}$ (Tabela I) junto aos dados de Johansen (1970) indicam um efeito substancial da temperatura na afinidade de oxigênio do sangue de Synbranchus.

Cinco espécies de ciclides (ciclidae da ordem Perciformes) foram estudados (Figs. 34-38). Das cinco espécies, duas têm o sangue com uma moderada e baixa afinidade pelo oxigênio $\left(P_{50}=7,5 \mathrm{~mm} \mathrm{Hg}\right.$ e $9,8 \mathrm{~mm} \mathrm{Hg}$ ) na ausência de $\mathrm{CO}_{2}$, enquanto que as outras três 

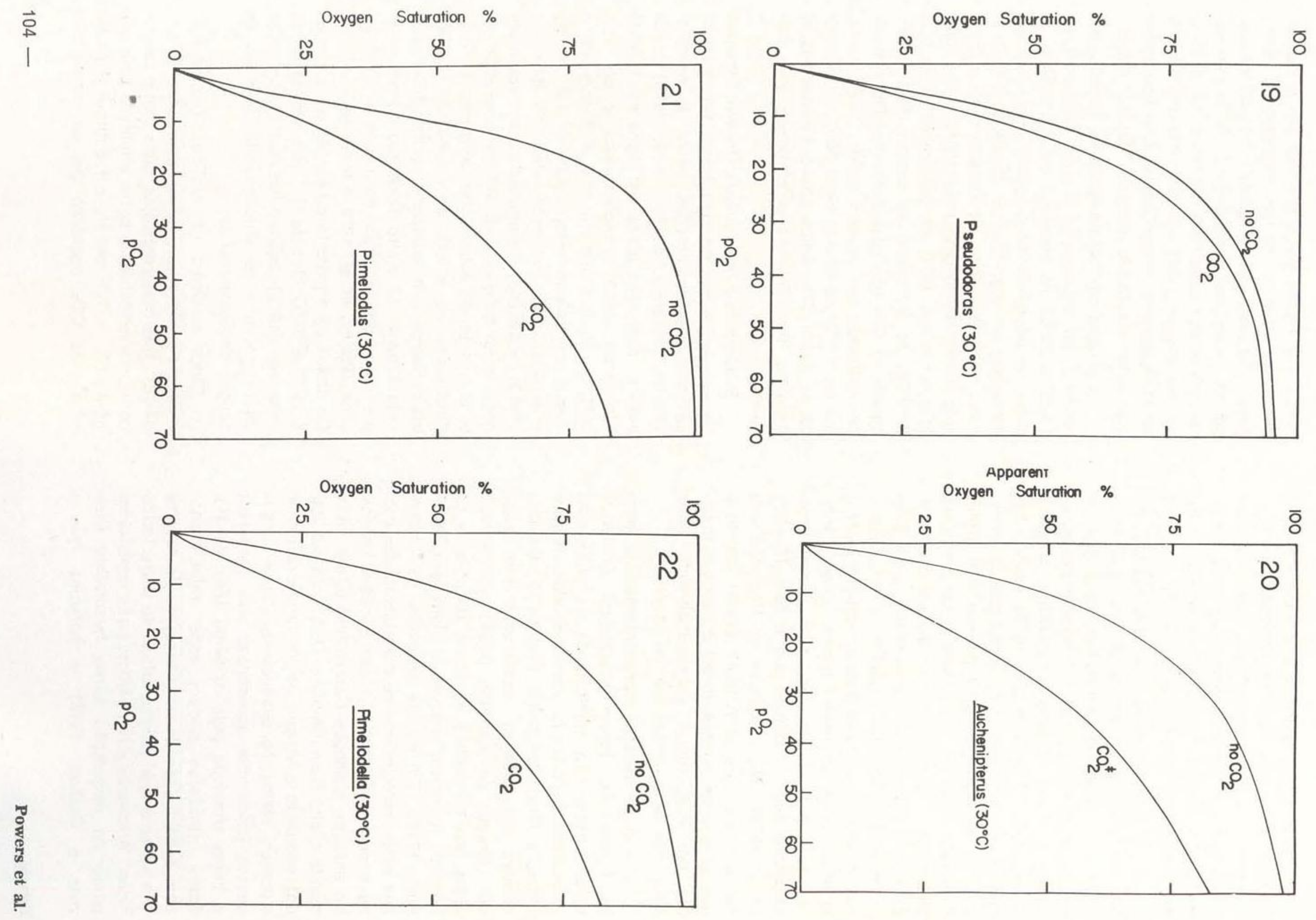

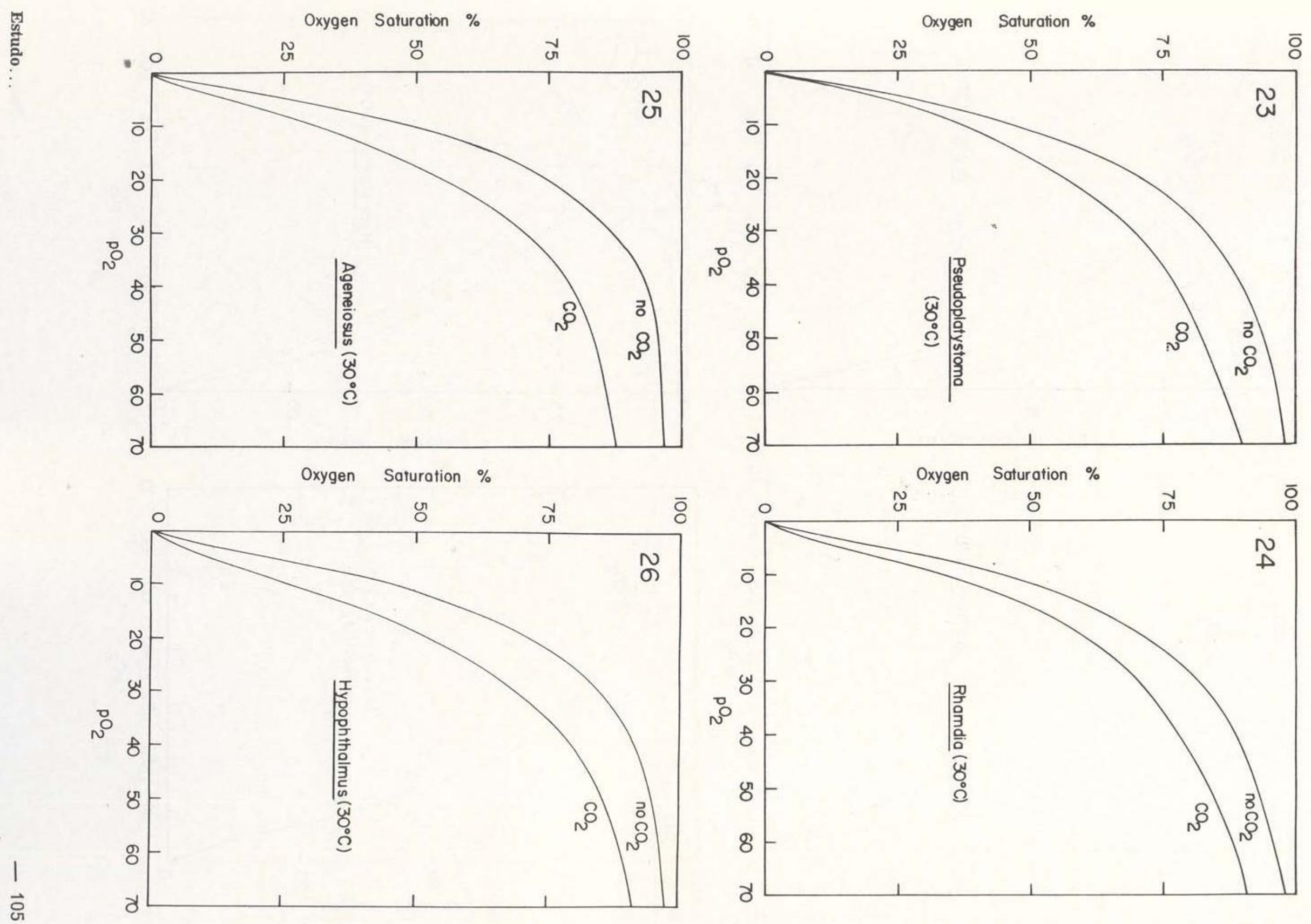

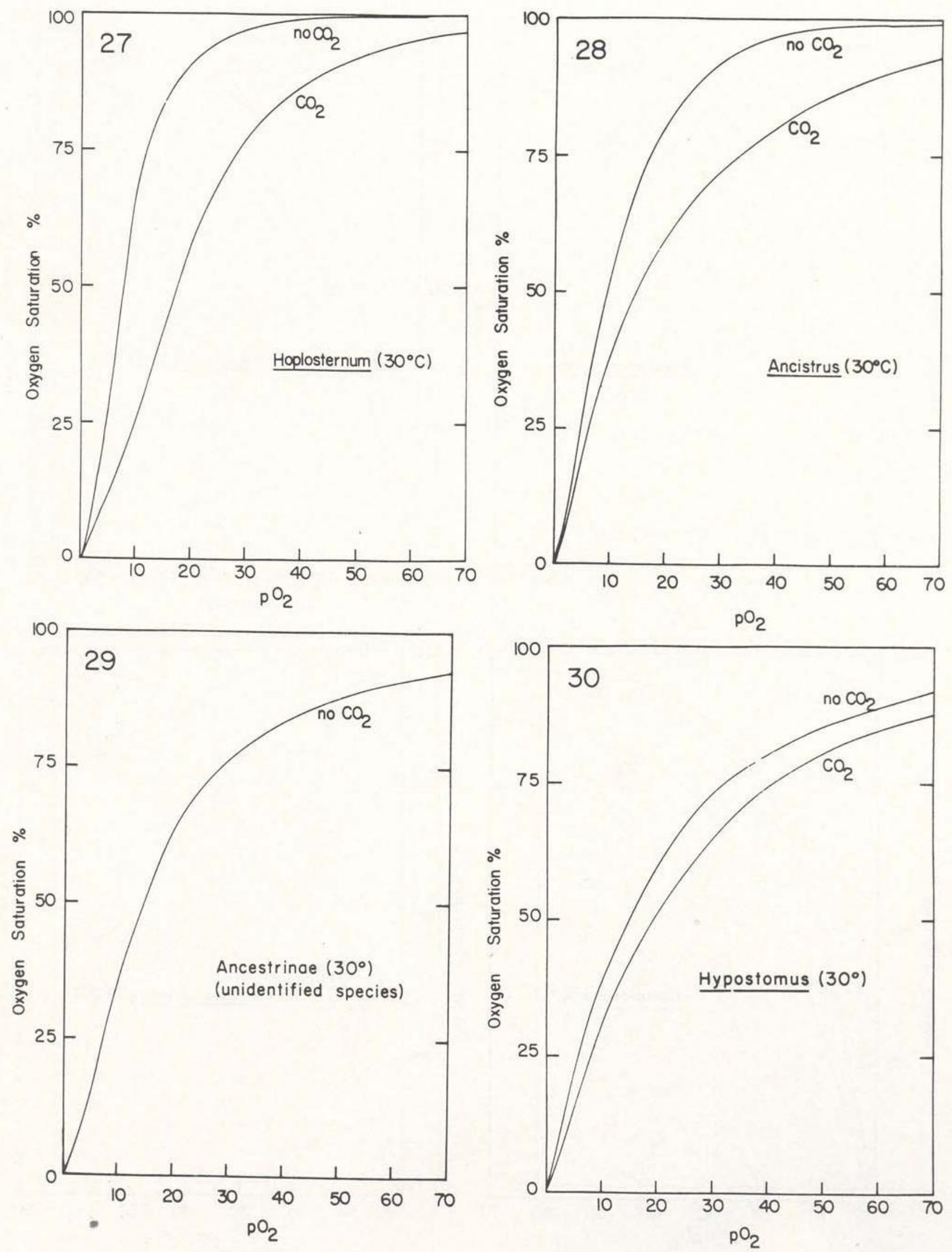
볼
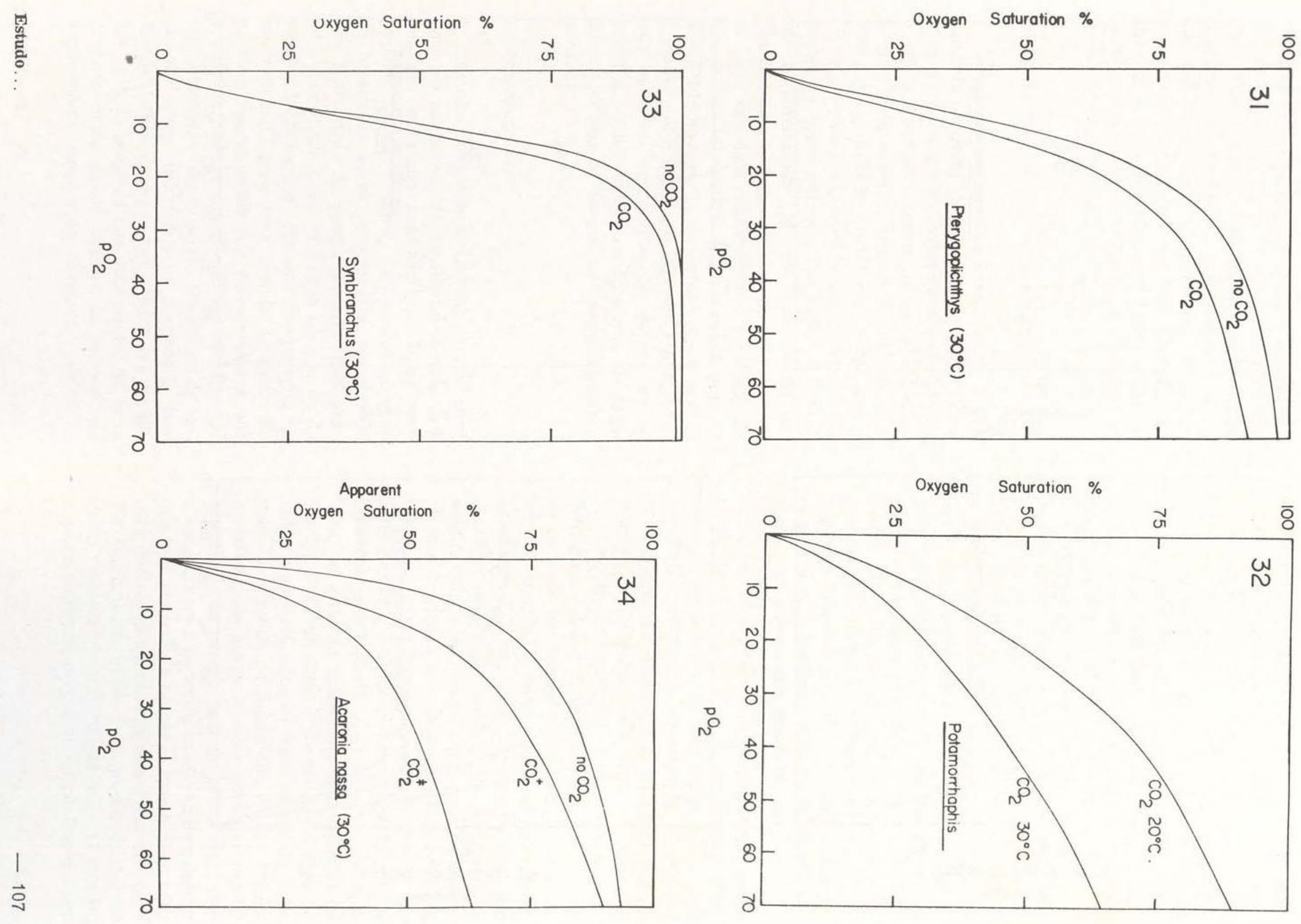

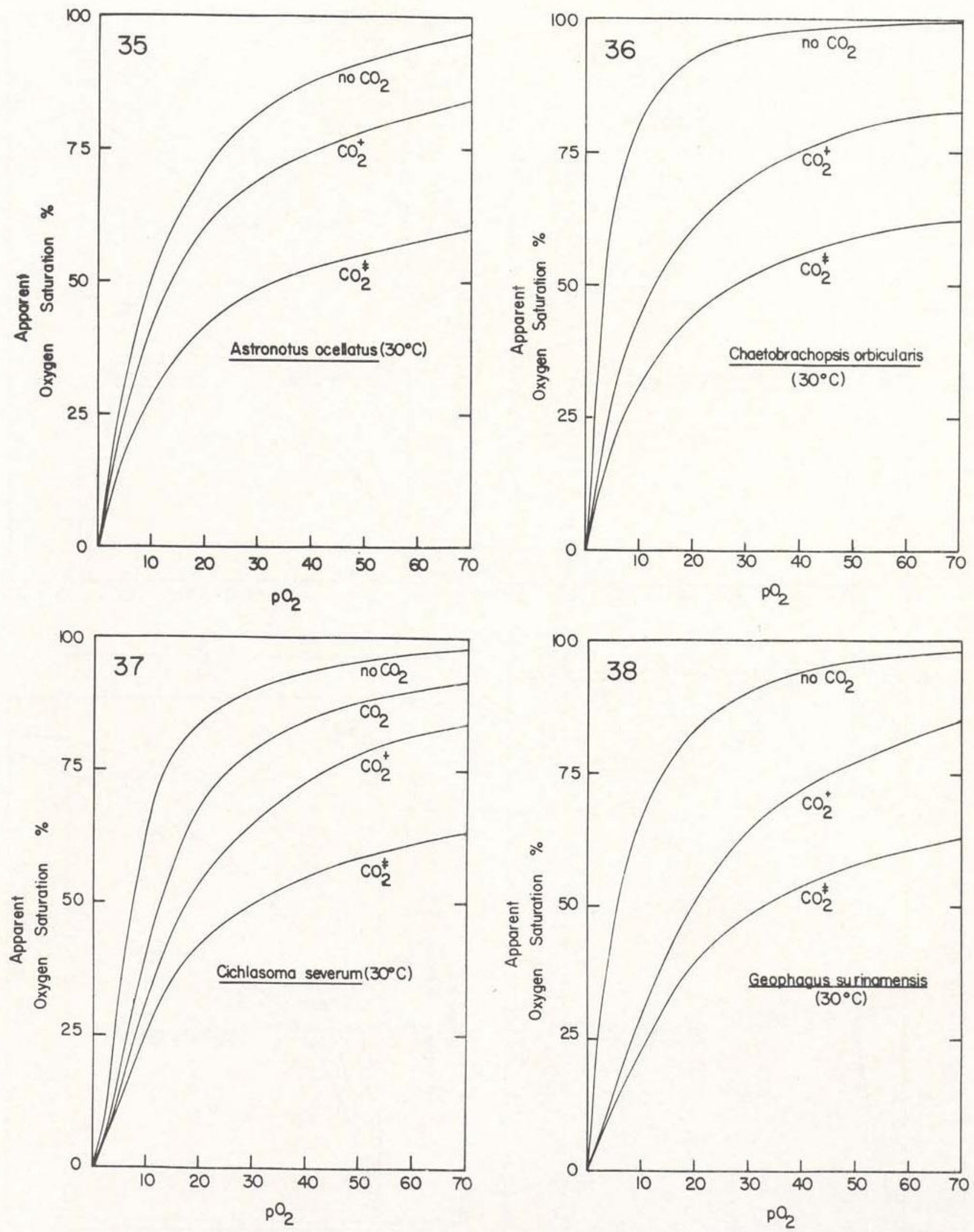
espécies têm o sangue com relativamente alta afinidade pelo oxigênio $P_{50}=4,2,5,0$ e $5,7 \mathrm{~mm}$ $\mathrm{Hg}$ ). Como alguns ciclídes são epibênticos e outros são pelágicos, suspeitamos que os que têm alta afinidade pelo oxigênio sejam para beneficiar-se das regiões bênticas de charcos e lagos em repouso. Todos os cinco ciclídes mostraram efeitos tanto Root quanto Bohr moderado (Tabela I) .

\section{pH DO SANGUE DE PEIXES DA AMAZÔNIA}

$\mathrm{O} \mathrm{pH}$ do sangue de peixes quando o $\mathrm{CO}_{2}$ não está presente no equilíbrio de gases numa faixa de 7,6 e 8,2 foi bastante alto tanto que o efeito Root foi presumivelmente inoperante $\left({ }^{2}\right)$. Neste aspecto, nossos resultados diferem dos de Willmer (1934) que notou que o $\mathrm{pH}$ do sangue era o mesmo e similar aos dos peixes de águas tropicais das Guianas Britânicas, sendo que os valores determinados por nós tem uma a duas unidades de $\mathrm{pH}$ mais baixa. Isto não está confirmando o resultado de Mangum et al. (1977) e apoia nosso parecer que $\mathrm{o} \mathrm{pH}$ do sangue de peixes da Amazônia é maior que o dado por Willmer (1934). Outros trabalhos em publicação (Wood et al. 1978a e 1978b) tratam do problema da capacidade tampão do sangue das espécies determinadas.

\section{DISCUSSÃO GERAL}

Quando Johansen \& Lenfant (1972) compararam as curvas de equilíbrio de três peixes de respiração branquial de águas temperadas (carpa, "catfish" e cavala) com os de respiração aérea selecionados, concluíram que a afinidade do sangue dos de respiração aérea tem mais baixa afinidade do que os de respiração branquial. Se uma comparação similar é feita para uma grande extensão de amostra representada por nossos dados sob condições uniformes $\left(\mathrm{T}=30^{\circ} \mathrm{C}, \mathrm{pCO}_{2} \cong 0\right)$ tais diferenças não existem. Os peixes de respiração aérea facultativa e obrigatória (ver Tabela I) tem o sangue com uma curva de dissociáção de oxigênio que está dentro da faixa ocupada pelos dados obtidos do sangue das espécies de respiração branquial. Estes re- sultados estão resumidos na Fig. 39. Em geral, a hipótese de que os de respiração aérea tem mais baixa afinidade que os de respiração branquial e como tal refletem uma adaptação evolucionária a um estilo de vida, não parece estar apoiada por estes dados. Talvez, a hipótese seja correta para anfíbios, porém o argumento, para uma grande variedade de espécies de peixes é pelo menos forçado. No entanto, uma razão prevaleceria de que o sangue dos de respiração aérea retém mais $\mathrm{CO}_{2}$ e ademais sob o pH do sangue o qual resulta in vivo uma baixa afinidade pelo oxigênio. Este raciocínio é fraco visto que na presença de $5.6 \% \mathrm{CO}_{2}$ não é significativamente característica a afinidade pelo oxigênio nos de respiração aérea e os de respiração branquial (Tabela I e Figs 2-38). Os dados em um par de espécie sistematicamente próximas Osteoglossum e Arapaima e Hoplias e Hoplerythrinus estão de acordo com a hipótese mas esses dados são insuficientes para um generalização.

Como uma diferenciação geral entre os de respiração branquial e os de respiração aérea não está apoiada por nossos dados, surge uma inquirição se outros parâmetros ecológicos podem ser tão importantes contribuintes na fórmula evolucionária para manter a homostasis fisiológica. Uma análise da informação da Tabela I e II e Fig. 2-38 indica que o equilíbrio de oxigênio está correlacionado com o habitat. Há uma correlação entre equilíbrio de oxigênio (quando $\circ \mathrm{CO}_{2}$ não está presente no gás) e o nicho ecológico do peixe ${ }^{3}$. Por exemplo, os dois extremos de habitat lótico para os de respiração branquial que estão em zonas lentas, onde o oxigênio é reduzido e no centro do rio, zona rápida e a saturação de oxigênio é relativamente alta (Tabela I e II) as curvas de equilíbrio de oxigênio $\left(\mathrm{pCO}_{2}=0\right)$ das espécies de habitat lótico de zona lenta são elementos de outro grupo cujo alcance está dentro da linha delgada e sólida da figura 40 . Peixes lóticos de habitat de zonas rápidas com um habitat específico de centro de igarapés e rios, têm o sangue com a curva de equilíbrio de oxigênio que são elementos de outro grupo cuja faixa está dentro da sólida e grossa linha da figura 40. Claramente, estes dois grupos de curvas estão discretamente acima de $\mathrm{pO}_{2}=13 \mathrm{~mm} \mathrm{Hg}$ e só se sobrepõe parcialmente por baixo desta 


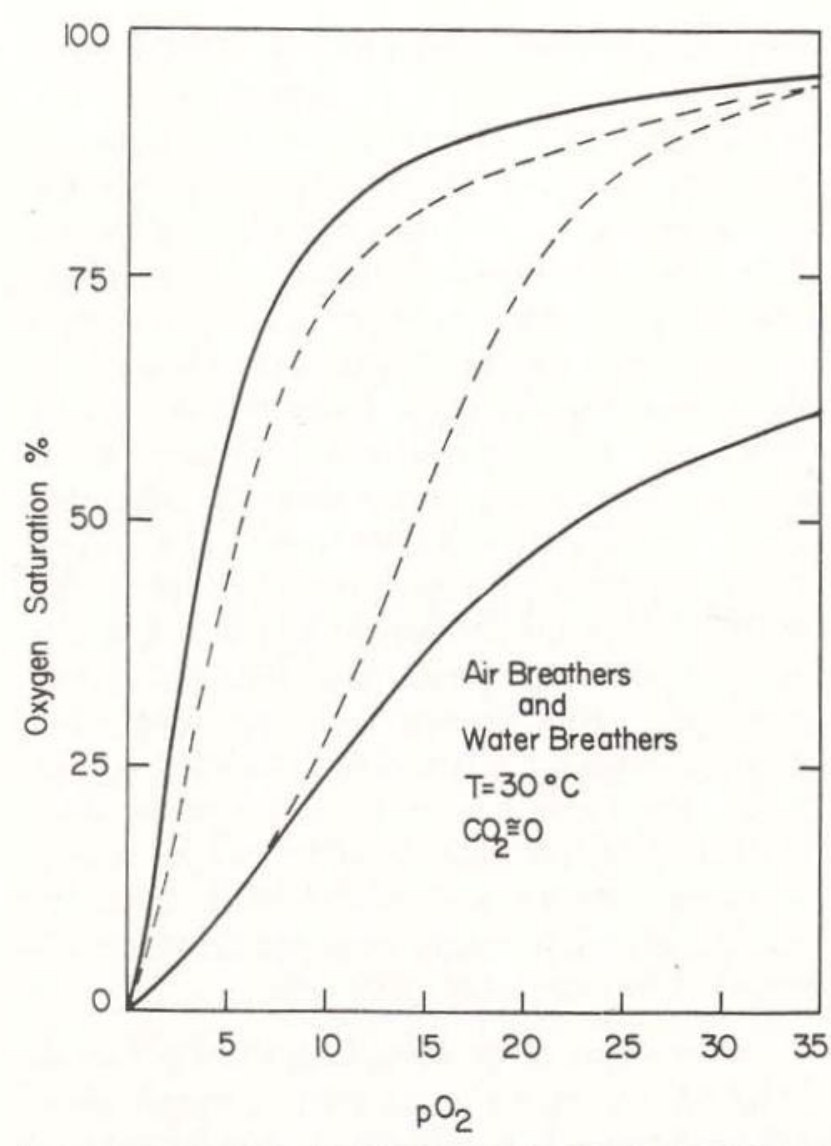

Fig. 39 - Uma comparação de afinidade de $\mathrm{Hb}-\mathrm{O}_{2}$ para peixes de respiração aérea e branquial. Todos os dados são determinados pela curva de equilíbrio sem $\mathrm{CO}_{2}$ no gás e à temperatura de $30^{\circ} \mathrm{C}$. A ordenada descreve a porcentagem de saturação de hemoglobina pelo oxigênio enquanto que a abscissa expressa $\circ \mathrm{pO}_{2}$ em mm $\mathrm{Hg}$. A curva de equilibrio para os de respiração aérea cai totalmente entre a linha ponteada da figura. A curva de equilíbrio para os de respiração branquial cai entre a curva de linha sólida da figura. As curvas para a respiração aérea caem dentro da faixa de respiração branquial.

$\mathrm{pO}_{2}$. Ademais, a figura 40 indica diferenças significativas, no alcance da curva de equilíbrio de oxigênio em peixes ciestes dois habitat. Espécies de zonas lenta têm mais alta afinidade pelo oxigênio e podem subseqüentemente viver em águas com baixo conteúdo de oxigênio do que as espécies de zonas rápidas de centros de rios e igarapés.

Espécies de zona rápida que vivem nas margens dos igarapés não têm natação rápida, como os peixes de centro de rio. O estilo de vida lento está associado com os níveis baixos de oxigênio na água do habitat e não é sur- presa que peixes das margens dos igarapés tenham a afinidade pelo oxigênio mais alta do que peixes do centro do rio (Fig. 40). Além disso, as hemoglobinas de peixes das margens do rio estão saturadas com oxigênio a uma baixa $\mathrm{pO}_{2}$ em comparação com aqueles peixes cujo habitat específico é o centro de rios de correnteza. Por outro lado, há uma pequena diferença entre afinidade pelo oxigênio nos peixes de habitat de zonas lenta e peixe de zona rápida, com habitat específico de margens e igarapés (Fig. 40).

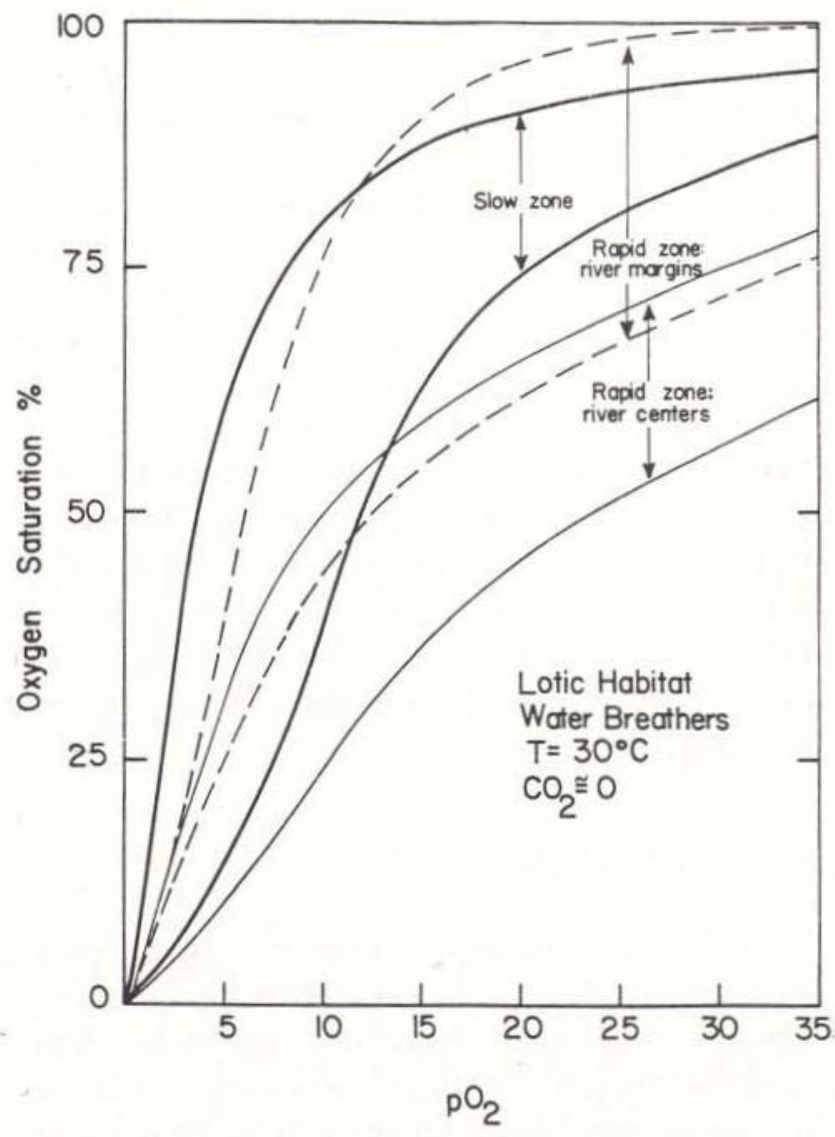

Fig. 40 - Uma comparação de afinidade de $\mathrm{Hb}-\mathrm{O}_{2}$ para respiração branquial de habitat 16 tico, mas de diferente sub-habitat e habitat especifico. A linha cheia inclui a faixa da curva de equilíbrio para espécies de zonas lenta A linha fina representa o limite da curva de equilíbrio das espécies de zonas rápidas de habitat específico de rios e médios de riachos. A linha quebrada representa o limite da curva para espécies de zona rápida que têm habitat especifico de riachos e margens de rios. Todos os dados são para $\mathrm{pCO}_{2}=\mathrm{O}, \mathrm{T}=30^{\circ} \mathrm{C}$. A ordenada representa a porcentagem de saturaçāo e abscissa a $\mathrm{pO}_{2} \mathrm{em} \mathrm{mm} \mathrm{Hg}$. 
Respiração branquial obrigatória de habitat lêntico suporta uma variedade de níveis de oxigênio e seu sangue está caracterizado por um extenso expectro de curva de equilíbrio de oxigênio. Como os habitats lênticos são, de algum modo, ecologicamente similares ao meio ambiente lótico de águas lentas, pode não ser surpreendente que os limites das curvas de equilíbrio de oxigênio para as espécies destes dois meios ambientes apresentem uma notável sobreposição de faixas .

Não objetivamos indagar sobre a $\mathrm{pCO}_{2}$ ambiental, o $\mathrm{pH}$ do sangue in vivo e a capacidade tamponante do sangue, os quais são constituintes importantes da ecologia fisiológica destes peixes. Nossos estudos têm mostrado que as propriedades dos peixes da Amazônia têm sido adaptadas a um eficiente intercâmbio de gases sob as condições predominantes de seu nicho ecológico. Espera-se que em futuros estudos em peixes de outras regiões geográficas possam elucidar se estas correlações com o habitat significam uma tendência evolucionária generalizada ou são condições ambientais características prevalecentes na bacia Amazônica.

\section{AGRADECIMENTOS}

A parte experimental deste trabalho foi completada a bordo do R/V "Alpha Helix" e patrocinado por a verba NSF (PCM 7506451) com apoio adicional da verba NSF, DEB 76-19877 (D.A.P.) e uma verba da The National Geographic Society (D.A.P.). Os participantes Noruegueses (H.J. e U. Fyhn) foram patrocinados por "Norwegian Research Council for Science and the Humanities".

Agradecemos ao capitão e tripulação da R/V "Alpha Helix" por sua ajuda e paciência. A comunicação relativa à ecologia de peixes e sua classificação sistemática e ecológica foi nenerosamente elaborada pelo Dr. Willian Fink ("Museum of Comparative Zoology, Harvard University") e Dr. Sally Woodin ("Johns Hopkins, University") .

Agradecemos em particular a ajuda do $\mathrm{Dr}$. Austen Riggs, sem a qual esta pesquisa não teria sido possível. Suas críticas a este manuscrito foram muito valiosas.

\section{SUMMARY}

We have examined the oxygen-affinity of the fresh, whole blood from representatives of 40 genera of Amazonian fishes. When all the aur breathnig fishes and all the water breathing fishes were considered, no differentiation in oxygen affinity could be distinguished, although in two cases of closely related species i.e. Osteoglossum, a water breather, versus Arapaima, an air breather, and Hoplias, a water breather, versus Hoplerythrinus, an air breather; the air breathers have bloods with lower oxygen affinity than do the water breathers. Significant differences in the oxygen affinity were fround when fishes were considered by habitat: the oxygen affinities were in general correlated with available environmental oxygen and relative oxygen demand of the fishes.

\section{BIBLIOGRAFIA}

ALEXANDER, R. MCN.

1965 - Structure and function in the catfish. J. Zool, 148, 88-152

BUNN, H.F. \& RIGGS, A.

1978 - A medida do efeito Bohr em hemoglobinas de peixe por focalização elétrica de Gel. Acta Amazonica 8(4): Suplemento. (Este volume)

CARTER, G. S.

1957 - Air Breaching. In The Physiology of Fishes (ed. Brown, M.E.) vol. 1, pp 65-79 Academic Press Inc. New York.

Carter, G.S. \& Beadle, L.C.

1931 - The fauna of the swamps of the Paraguayan Chaco in relation to its environment. - II. Respiratory adaptions in the fishes. Linn. J. Zool. 37, 327-368. 23 plates.

FINK, W.L. \& FINK, S.V.

1978 - A Amazônia Central e seus peixes. Acta Amazonica 8(4): Suplemento. (Este vo. lume).

FyhN, U.E.H.; FyhN, H.J.; DAvis, B.J.; POWers,

D.A.; FINK, W.L. \& GARLICK, R.L.

1978 - Heterogeneidade de hemoglobina nos peixes da Amazônia. Acta Amazonica 8(4) : Suplemento. (Este volume).

GARLICK, R.L.; BUNN, H.F.; FYHN, H.J.; FYhN, U.E.H.; MARTIN, J.P.; Noble, R.W. \& POWers, D.A.

1978 - Estudos funcionais na hemoglobina de componentes separados de um bagre de respiração aérea Hoplosternum littora le (Hancock). Acta Amazonica 8(4): Suplemento. (Este volume)

JOHANSEN, $\mathbf{K}$.

1966 - Air breathing in the teleost Synbranchus marmoratus. Comp. Biochem. Prysiol. $18: 387-395$. 
JOHANSEN, $\mathbf{K}$.

1970 - Air breathing in Fishes, In Fish Physio. logy, (eds Hoar, W.S. and Randall, D.J.) vol. 4 pp. 361-411. Academic Press.

JohANSEN, K. \& Lenfant, C.

1972 - A Comparative Approach to the Adaptability of $\mathrm{O}_{2}$ - $\mathrm{Hb}$ Affinity of Hemoglobin and Red Cell Acid Base Status (eds. Astrup, P. and Rorth, M.) Academic Press, Munksgaard, Copenhagen, Denmark, pp. 752-783.

Johansen, $\mathbf{K}$. \& Lenfant, C.

1967 - Respiratory function in the South American lungish, Lepidosiren para doxa. J. Exptl. Biol. 46, 205-218.

Kramer, D.L. \& Graham, J.B.

1976 - Synchronous air breathing, a social component of respiration in fishes. Copeia 1976, 669-697.

LENFANT, C. \& Johansen, $\mathrm{K}$.

1967 - Respiratory adaptations in selected amphibians. Resp. Physiol. 2, 247-260.

Manwell, C.

1958 - Ontogeny of hemoglobin is the skate Raja binoculata Science 128, 419-420.

Mangum, C.P.; Haswell, M.S. \& Johansen, K.

1977 - Low Salt and high pH in the blood of Amazonian fishes. J. Exp. Zool. 200, 163-168.

MCCUTCHEON \& HALL

1937 - Hemoglobin in the Amphibia. J. Cell. Comp. Physiol. 9, 191-197.

FARMER, M.; FYhN, H.J.; FYHN, U.E.H. \& NOBLE, R.W.

1978 - Ocorrência de hemoglobinas de efeito Root em peixes amazônicos. Acta Amazonica 8(4): Suplemento. (Este volume).

Phelps, C.; FARMer, M.; Fyhn, H.J.; Fyhn, U. E. H.; Garlick, R.L.; Noble, R.W. \& Powers, D.A.

1978a - Equilíbrio e cinética de união de oxigênio e monóxido de carbono à hemo- globina do peixe pulmonado sul amerlcano Lepidosiren paradoxa. Acta Amazonica 8(4): Suplemento. (Este volume).

Phelps, C.; Garlick, R.L.; Powers, D.A.; Noble, R.W. \& MARTIN, J.P.

1978 - Equilíbrio e cinética de ligação de oxigênio e monóxido de carbono à hemoglobina de teleosteo Synbranchus mar. moratus. Acta Amazonica 8(4) : Suplemento. (Este volume).

ReIss, F,

1977 - Qualitative and quantitative investigations on the macrobenthic fauna of Central Amazon Lakes. I. Lago Tupe, a black water lake on the lower Rio Negro. Amazoniana 4, 203-235.

RIGGS, A.; FYHN, H.J.; FYHN, U.E.H. \& NOBLE, R.W.

1978 - Estudos das propriedades funcionais da hemoglobina de Hoplias malabaricus e Hoplerythrinus unitaeniatus. Acta Amazonica 8(4): Suplemento. (Este volume).

TAYLOR, M

1913 - The development of Synbranchus marmoratus. Quart. J. Microscop. Sci. 59. 1-51.

THOMPSON, $\mathrm{K}$.

1969 - The biology of the lobe-finned fishes. Biol. Rev. 44, 91.

WILLMER, E.N.

1934 - Some observations on the respiration of certain tropical fresh-water fish. J. Exp. Biol. 11. 283-306.

WOOD, S.; Weber, R.E. \& PoWers, D.A.

1978 - Propriedades respiratórias do sangue e soluções de hemoglobina da piranha. Acta Amazonica 8(4) : Suplemento. (Este volume).

WOOD, S.C.; Weber, R.E. \& DAVIS, B.J.

1978 - Efeitos da respiração aérea sob o ba lanço ácido-base no bagre cascudo $\mathbf{H y}$ postomus sp. Acta Amazonica 8(4) : Suplemento. (Este volume). 